\title{
PRESERVATION TECHNOLOGY INVESTMENT, TRADE CREDIT AND PARTIAL BACKORDERING MODEL FOR A NON-INSTANTANEOUS DETERIORATING INVENTORY
}

\author{
Abu Hashan Md Mashud ${ }^{1}$, Hui-Ming WeE $^{2, *}$ and Chiao-Ven Huang ${ }^{2}$
}

\begin{abstract}
In a perfectly transparent and competitive market, suppliers must provide a competitive pricing and service for their customers. The aim of this study is to provide an insight into how preservation technology and credit financing could be used both to reduce the deterioration rate as well as to provide flexible financing for retailers. The methodology is to optimize the cycle length, selling price, the amount of preservation technology and credit financing using inventory theory. The result derived is an optimal total profit per unit time for the system. Finally, using MATLAB 2017a, it is shown graphically that the profit function is concave. The sensitivity analysis is illustrated using Lingo 17 . The study not only provides insights to business managers in making wise managerial decisions, it also enables them to weigh the pro and con of implementing preservation technology and credit financing.
\end{abstract}

Mathematics Subject Classification. 90B05, 90B30.

Received April 7, 2019. Accepted September 27, 2019.

\section{INTRODUCTION}

Inventory is defined as idle stocks in a supply chain. The management of inventory is critical factor in the dayto-day operation of an enterprise, therefore a proper system to manage inventory is critical. One of the key factors to consider in inventory modeling is deterioration. Deterioration is the evaporation, decay or damage of inventory. Inventory has been the focus of many researches for over a century. Mishra [17] projected an inventory model for controllable deterioration with time-varying demand and time-varying holding cost. Mishra [16] presented an inventory model with controllable deterioration rate and time-dependent demand. Pandey et al. [22] established an inventory model with negative exponential demand and probabilistic deterioration under backlogging. Nobil et al. [20] developed a model for single machine lot scheduling problem for negative exponential deteriorating items. Nobil et al. [21] projected a model for economic lot size problem for cleaner manufacturing system with another interesting parameter warm-up period. A two-warehouse model with increasing demand under timevarying deterioration is developed by Sett et al. [26]. Sarkar and Sarkar [25] developed an inventory model with partial backlogging and stock dependent demand. Palanivel and Uthayakumar [24] presented an inventory

Keywords. non-instantaneous deterioration, price dependent demand, partial backlogging, preservation technology, trade credit.

1 Department of Mathematics, Hajee Mohammad Danesh Science and Technology University, 5200 Dinajpur, Bangladesh.

2 Department of Industrial and Systems Engineering, Chung Yuan Christian University, 200 Chung-Pei Rd., 32023 Chung-li, Taiwan.

${ }^{*}$ Corresponding author: weehm@cycu.edu.tw 
TABLE 1. A comparison of the present study with the previous researches.

\begin{tabular}{|c|c|c|c|c|c|}
\hline Authors & Demand pattern & Deterioration & $\begin{array}{l}\text { Preservation } \\
\text { technology }\end{array}$ & Shortages & Trade credit \\
\hline Dye and Hsieh [7] & Constant & Time-dependent & Yes & $\begin{array}{l}\text { Partial Back- } \\
\text { ordering }\end{array}$ & No \\
\hline Hsieh and Dye [10] & Time-dependent & Constant & Yes & No & No \\
\hline He and Huang [9] & Price-dependent & Constant & Yes & No & No \\
\hline Dye $[6]$ & Constant & Non-instantaneous & Yes & $\begin{array}{l}\text { Partial backo- } \\
\text { rdering }\end{array}$ & No \\
\hline Zhang et al. [36] & Price dependent & Constant & Yes & No & No \\
\hline Liu et al. [13] & Price dependent & Constant & Yes & No & No \\
\hline Lu et al. [14] & $\begin{array}{l}\text { Price and stock } \\
\text { dependent }\end{array}$ & Constant & No & No & No \\
\hline Jaggi et al. [11] & Price-dependent & Non-instantaneous & No & $\begin{array}{l}\text { Complete } \\
\text { backordering }\end{array}$ & Yes \\
\hline Li et al. [12] & Price-dependent & Non-instantaneous & Yes & No & No \\
\hline Tiwari et al. [33] & Price-dependent & Non-instantaneous & No & $\begin{array}{l}\text { Partial backo- } \\
\text { rdering }\end{array}$ & Yes \\
\hline Mishra et al. [18] & Price-dependent & Cons & Yes & No & Yes \\
\hline This paper & Price dependent & Non-instantaneous & Yes & $\begin{array}{l}\text { Partial backo- } \\
\text { rdering }\end{array}$ & Yes \\
\hline
\end{tabular}

model for imperfect items with stock dependent demand under permissible delay in payments. Shaikh et al. [28] presented a model considering stock and price sensitive demand under fully backlogged shortages. Mashud et al. [15] developed an inventory model for non-instantaneous inventory model with same demand. Nobil et al. [19] developed an economic production quantity model with and without shortages for imperfect products. Dey et al. [5] projected an inventory model considering price dependent demand with setup cost reduction.

In terms of preservation of products, Dye and Hsieh [7] developed an inventory model considering the investment in preservation technology. Dye [6] also developed a non-instantaneous deteriorating inventory model with preservation technology. Singh et al. [29] developed an EOQ model for stock-dependent demand deteriorating items with preservation technology; while Yang et al. [35] introduced optimal dynamic trade credit and preservation in their model.

Goyal [8] was one of the first researchers who developed an EOQ model under permissible delays in payments. Aggarwal and Jaggi [1] introduced an ordering policy for deteriorating items under permissible delays in payments. Tsao and Sheen [34] considered deteriorating items inventory model with price and time-dependent demand under permissible delays in payments. Pal [23] developed a production inventory model for imperfect products with permissible delay in payments under shortages. Yang et al. [35] considered the preservation technology investment to control the deterioration for a time-dependent demand rate under trade credit policy. Teng et al. [30] developed an EOQ model with trade credit financing for non-decreasing demand. Chen and Teng [3] modified this model by introducing upstream and downstream trade credit policy in his time-varying deteriorating model with cash flow. Lastly, Tiwari et al. $[31,32]$ developed a non-instantaneous deteriorating inventory model considering inflation and trade credit policy in a two-warehouse environment. A comparison of the present study with the previous researches is shown in Table 1.

The objective of this paper is to optimize the cycle length, selling price considering preservation technology. Three numerical examples were used to illustrate the theory. Graphical representations are used to illustrate the results. 
TABLE 2. Notations.

\begin{tabular}{lll}
\hline \hline Notations & Units & Description \\
\hline$c$ & $\$ /$ order & Purchasing cost per order \\
$c_{1}$ & $\$ /$ unit & Holding cost per unit \\
$c_{2}$ & $\$ /$ unit & Shortage cost per unit \\
$c_{3}$ & $\$ /$ unit & Lost sale cost per unit \\
$A$ & $\$ /$ unit & Replenishment cost per order \\
$\delta$ & $\$ /$ unit & Backlogging parameter \\
$\theta$ & Constant & Deterioration rate \\
$M$ & Month & Period of permissible delay in payments offered by the supplier \\
$a$ & & All factors affecting price other than costs $(e . g$. income, fashion $)$ \\
$b$ & & The slope of the demand curve \\
$I_{e}$ & $\$ /$ unit & The rate of interest earned by the retailer \\
$I_{c}$ & $\$ /$ unit & The rate of interest payable by the supplier \\
$R$ & units & Maximum shortage quantity per cycle \\
$S$ & units & Initial inventory level \\
$Q$ & units & Order size per cycle \\
$X$ & units & Total inventory cost \\
$t_{1}$ & month & The time point at which the deterioration starts \\
$\pi(p, \xi, T)$ & $\$ /$ month & The total profit per unit time \\
\hline Dependent & Variable & \\
\hline$t_{2}$ & month & The time point at which the shortages are allowed \\
\hline Decision variables & \\
\hline$p$ & month & Unit selling price \\
$T$ & month & The total length of the inventory cycle \\
$\xi$ & $\$ /$ unit & Preservation technology cost \\
\hline
\end{tabular}

\section{Notations AND ASSUMPtions}

The notations as seen in Table 2 followed by the assumptions in Section 2.1 were utilized to develop the inventory models.

\subsection{Assumptions}

(1) The model considered a linear price-dependent demand pattern $D(p)=a-b p$ (i.e. demand function depends on price for a single deteriorating item).

(2) The considered deterioration rate $\theta(0<\theta \ll 1)$ is constant and depends on the stock amount.

(3) No replacement or repairs on deteriorating products were considered for the whole period.

(4) Lead-time is negligible and the replenishment rate is infinite.

(5) The total planning horizon considered in the inventory system is infinite.

(6) The relationship between the deterioration rate and the preservation technology investment parameter always satisfies the conditions $\frac{\partial m(\xi)}{\partial \xi}<0, \frac{\partial^{2} m(\xi)}{\partial \xi^{2}}>0$. The research considered that $m(\xi)=\mathrm{e}^{-a_{1} \xi}$; where $m(\xi)$ is the deterioration rate with the investment of preservation technology, $\theta$ is the deterioration rate without the preservation technology investment, and $a_{1}$ is the sensitive parameter of investment to the deterioration rate which is similar as Mishra et al. [18] and He and Huang [9].

(7) The backlogging rate during the stock out period is considered as a variable dependent on the length of waiting time for the next replenishment. Therefore, the backlogging rate for negative inventory is given by $\frac{1}{1+\delta(T-t)}$, where $\delta$ is a backlogging parameter, and $(T-t)$ is the waiting time. 


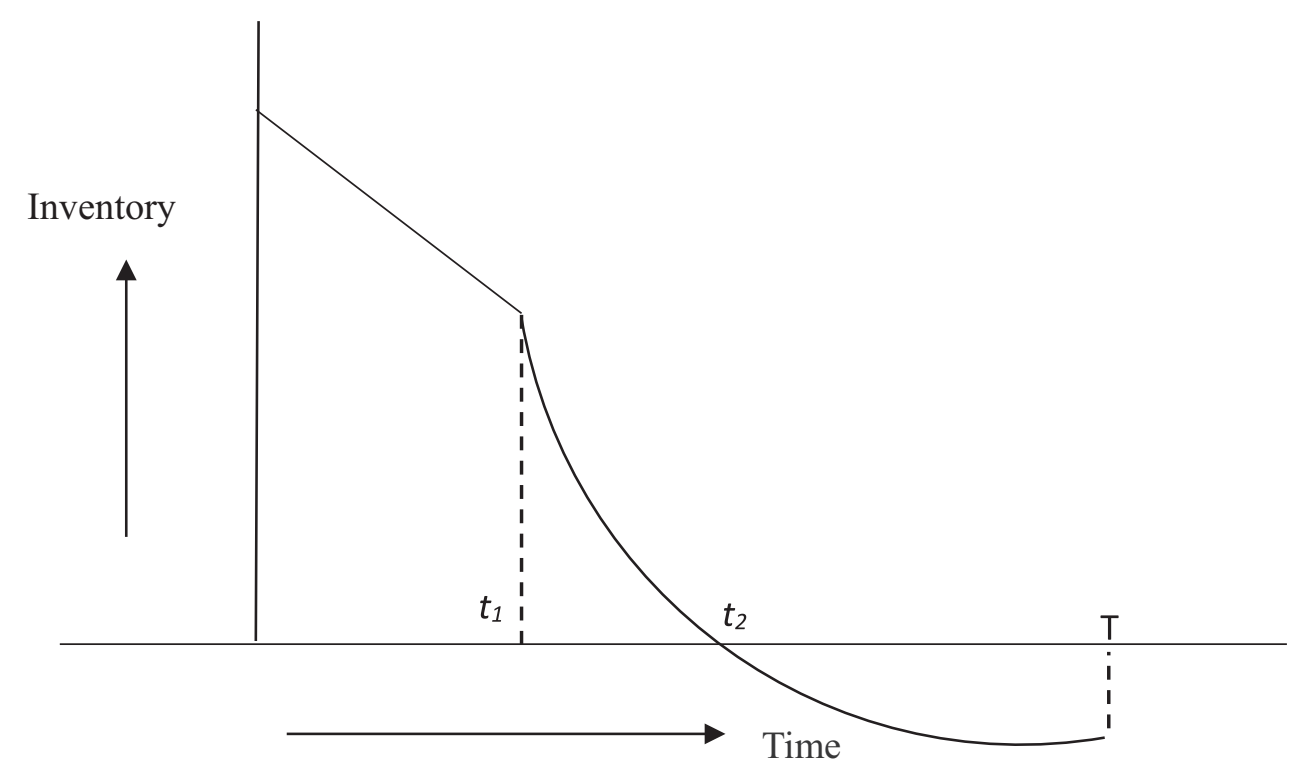

FiguRE 1. Graphical presentation of inventory vs. time.

\section{Mathematical Formulations}

Figure 1 shows the graphical demonstration of inventory vs. time wherein the inventory level at any time interval between $0 \leq t \leq T$ is represented by $I(t)$. It is important to present that the level of inventory $I(t)$ was portrayed due to demand in the period $\left[0, t_{1}\right]$ and it dropped to zero at $t=t_{2}$ owing to the deterioration and demand in the period $\left[t_{1}, t_{2}\right]$. Afterwards, shortages were permitted to take place and the total demand in the period $\left[t_{2}, T\right]$ is partially backordered.

The following differential equations illustrate the inventory model:

Change in inventory level,

$$
\frac{\mathrm{d} I_{1}(t)}{\mathrm{d} t}=-(a-b p) \quad 0<t \leq t_{1}
$$

with the initial and boundary conditions as $I_{1}(t)=S$ at $t=0$.

The solution for equation (3.1) is as follows:

$$
I_{1}(t)=S-(a-b p) t, 0<t \leq t_{1}
$$

and

$$
\frac{\mathrm{d} I_{2}(t)}{\mathrm{d} t}+\theta m(\xi) I_{2}(t)=-(a-b p) \quad t_{1}<t \leq t_{2}
$$

with the boundary condition $I_{2}(t)=0$ at $t=t_{2}$, the solution for equation (3.3) is as follows:

$$
I_{2}(t)=\frac{(a-b p)}{\theta m(\xi)}\left(\mathrm{e}^{\theta m(\xi)\left(t_{2}-t\right)}-1\right) \quad t_{1}<t \leq t_{2}
$$

where $I(t)$ is continuous at $t=t_{1}$, hence $I_{1}\left(t_{1}\right)=I_{2}\left(t_{1}\right)$ resulting in,

$$
S=(a-b p) t_{1}+\frac{(a-b p)}{\theta m(\xi)}\left(\mathrm{e}^{\theta m(\xi)\left(t_{2}-t_{1}\right)}-1\right) .
$$


At time, $t=t_{2}$, the inventory level is zero. For $t>t_{2}$, shortage occurs, the inventory level at any time $t$ is directed by the differential equation

$$
\frac{\mathrm{d} I_{3}(t)}{\mathrm{d} t}=\frac{-(a-b p)}{1+\delta(T-t)} \quad t_{2}<t \leq T
$$

with the boundary condition $I_{3}(t)=0$ at $t=t_{2}$, one has:

$$
I_{3}(t)=\frac{(a-b p)}{\delta}\left\{\log (1+\delta(T-t))-\log \left(1+\delta\left(T-t_{2}\right)\right)\right\} \quad t_{2}<t \leq T .
$$

The maximum amount of demand, which is the backlogged is given as follows:

$$
R=-I_{3}(T)=\frac{(a-b p)}{\delta}\left\{\log \left(1+\delta\left(T-t_{2}\right)\right)\right\} .
$$

Hence, the total order quantity per cycle is:

$$
\begin{aligned}
Q & =S+R \\
& =(a-b p) t_{1}+\frac{(a-b p)}{\theta m(\xi)}\left(\mathrm{e}^{\theta m(\xi)\left(t_{2}-t_{1}\right)}-1\right)+\frac{(a-b p)}{\delta}\left\{\log \left(1+\delta\left(T-t_{2}\right)\right)\right\} .
\end{aligned}
$$

The holding cost in the entire cycle is set as

$$
\begin{aligned}
\mathrm{IHC} & =c_{1} \int_{0}^{t_{1}} I_{1}(t) \mathrm{d} t+c_{1} \int_{t_{1}}^{t_{2}} I_{2}(t) \mathrm{d} t \\
& =c_{1}\left[S t_{1}-\frac{(a-b p) t_{1}^{2}}{2}-\frac{(a-b p)}{\theta^{2} m(\xi)^{2}}\left(1-\mathrm{e}^{\theta m(\xi)\left(t_{2}-t_{1}\right)}+\theta m(\xi)\left(t_{2}-t_{1}\right)\right)\right] .
\end{aligned}
$$

The backorder cost in the entire cycle is set as

$$
\begin{aligned}
\mathrm{BC} & =C_{2} D \frac{1}{\delta}\left[\int_{t_{2}}^{T}\left\{\log \left(1+\delta\left(T-t_{2}\right)\right)-\log (1+\delta(T-t))\right\} \mathrm{d} t\right] \\
& =c_{2}\left[\left(R+\frac{D}{\delta}\left(T-t_{2}\right)\right)-\frac{D}{\delta^{2}}\left(1+\delta\left(T-t_{2}\right)\right) \log \left(1+\delta\left(T-t_{2}\right)\right)\right] .
\end{aligned}
$$

The opportunity cost due to lost sales in the entire cycle is specified in the form

$$
\begin{aligned}
\mathrm{LSC} & =c_{3} \int_{t_{2}}^{T}\left\{1-\frac{1}{1+\delta(T-t)}\right\}(a-b p) \mathrm{d} t \\
& =\frac{c_{3}(a-b p)}{\delta}\left\{\delta\left(T-t_{2}\right)-\log \left(1+\delta\left(T-t_{2}\right)\right)\right\} .
\end{aligned}
$$

The total purchase cost per cycle is given in the form

$$
\mathrm{PC}=c Q=c\left[(a-b p) t_{1}+\frac{(a-b p)}{\theta m(\xi)}\left(\mathrm{e}^{\theta m(\xi)\left(t_{2}-t_{1}\right)}-1\right)+\frac{(a-b p)}{\delta}\left\{\log \left(1+\delta\left(T-t_{2}\right)\right)\right\}\right] .
$$

The total sales revenue in the entire cycle is known in the form

$$
\mathrm{SR}=p\left[(a-b p) t_{2}+\frac{(a-b p)}{\delta}\left\{\log \left(1+\delta\left(T-t_{2}\right)\right)\right\}\right] .
$$


The preservation technology cost in the entire cycle is

$$
\mathrm{PTC}=\xi T .
$$

For the supplier, the period of permissible delay in payment offered $(M)$ has different scenarios which are shown as:

Scenario $1 \quad 0<M \leq t_{1}$.

Scenario $2 \quad t_{1}<M \leq t_{2}$.

Scenario $3 \quad t_{2}<M \leq T$.

Equation (3.16) displays the interest earned bearing in mind scenario 1, when $0<M \leq t_{1}$.

$$
\begin{aligned}
\mathrm{IE}_{1} & =p I_{e} \int_{0}^{t_{2}} \int_{0}^{t}(a-b p) \mathrm{d} u \mathrm{~d} t+\frac{p I_{e}(a-b p) t_{2}}{\delta} \log \left(1+\delta\left(T-t_{2}\right)\right) \\
& =\frac{p I_{e}(a-b p) t_{2}^{2}}{2}+\frac{p I_{e}(a-b p) t_{2}}{\delta} \log \left(1+\delta\left(T-t_{2}\right)\right) .
\end{aligned}
$$

The interest paid to the supplier for this case is

$$
\begin{aligned}
\mathrm{IC}_{1} & =c I_{c} \int_{M}^{t_{1}} I_{1}(t) \mathrm{d} t+c I_{c} \int_{t_{1}}^{t_{2}} I_{2}(t) \mathrm{d} t \\
& =c I_{c}\left[S\left(t_{1}-M\right)-(a-b p) \frac{\left(t_{1}^{2}-M^{2}\right)}{2}\right]-\frac{c I_{c}(a-b p)}{(\theta m(\xi))^{2}}\left[\left(1-\mathrm{e}^{\theta m(\xi)\left(t_{2}-t_{1}\right)}\right)+\theta m(\xi)\left(t_{2}-t_{1}\right)\right] .
\end{aligned}
$$

Therefore, the total profit is

where

$$
\pi^{1}(p, \xi, T)=\frac{X}{T}
$$

$$
\begin{aligned}
X= & \left(\mathrm{SR}-\mathrm{OC}-\mathrm{PC}-\mathrm{IHC}-\mathrm{BC}-\mathrm{LSC}-\mathrm{PTC}+\mathrm{IE}_{1}-\mathrm{IC}_{1}\right) \\
= & p\left[(a-b p) t_{2}+\frac{(a-b p)}{\delta}\left\{\log \left(1+\delta\left(T-t_{2}\right)\right)\right\}\right]-A \\
& -c\left[(a-b p) t_{1}+\frac{(a-b p)}{\theta m(\xi)}\left(\mathrm{e}^{\theta m(\xi)\left(t_{2}-t_{1}\right)}-1\right)+\frac{(a-b p)}{\delta}\left\{\log \left(1+\delta\left(T-t_{2}\right)\right)\right\}\right] \\
& -c_{1}\left[S t_{1}-\frac{(a-b p) t_{1}^{2}}{2}-\frac{(a-b p)}{\theta^{2} m(\xi)^{2}}\left(1-\mathrm{e}^{\theta m(\xi)\left(t_{2}-t_{1}\right)}+\theta m(\xi)\left(t_{2}-t_{1}\right)\right)\right] \\
& -c_{2}\left[\left(R+\frac{D}{\delta}\left(T-t_{2}\right)\right)-\frac{D}{\delta^{2}}\left(1+\delta\left(T-t_{2}\right)\right) \log \left(1+\delta\left(T-t_{2}\right)\right)\right] \\
& -\frac{c_{3}(a-b p)}{\delta}\left\{\delta\left(T-t_{2}\right)\right]+\frac{p I_{e}(a-b p) t_{2}^{2}}{2}+\frac{p I_{e}(a-b p) t_{2}}{\delta} \log \left(1+\delta\left(T-t_{2}\right)\right) \\
& -\xi T-c I_{c}\left[S\left(t_{1}-M\right)-(a-b p) \frac{\left(t_{1}^{2}-M^{2}\right)}{2}\right]+\frac{c I_{c}(a-b p)}{(\theta m(\xi))^{2}}\left[\left(1-\mathrm{e}^{\theta m(\xi)\left(t_{2}-t_{1}\right)}\right)+\theta m(\xi)\left(t_{2}-t_{1}\right)\right]
\end{aligned}
$$

The corresponding optimization problem is as follows:

Problem 3.1. $\pi^{1}(p, \xi, T)=\frac{X}{T}$, subject to constraints $0<M \leq t_{1}$.

For scenario 2, the interest earned is measured when $t_{1}<M \leq t_{2}$ as seen in equation (3.19).

$$
\begin{aligned}
\mathrm{IE}_{2} & =p I_{e} \int_{0}^{t_{2}} \int_{0}^{t}(a-b p) \mathrm{d} u \mathrm{~d} t+\frac{p I_{e}(a-b p) t_{2}}{\delta} \log \left(1+\delta\left(T-t_{2}\right)\right) \\
& =\frac{p I_{e}(a-b p) t_{2}^{2}}{2}+\frac{p I_{e}(a-b p) t_{2}}{\delta} \log \left(1+\delta\left(T-t_{2}\right)\right)
\end{aligned}
$$


For this case, the interest paid to the supplier is

$$
\begin{aligned}
\mathrm{IC}_{2} & =c I_{c} \int_{M}^{t_{2}} I_{2}(t) \mathrm{d} t \\
& =c I_{c}\left[\frac{(a-b p)}{(\theta m(\xi))^{2}}\left(\mathrm{e}^{\theta m(\xi)\left(t_{2}-M\right)}-1\right)-\frac{(a-b p)\left(t_{2}-M\right)}{\theta m(\xi)}\right] .
\end{aligned}
$$

Hence, the total profit is

$$
\pi^{2}(p, \xi, T)=\frac{X}{T}
$$

where

$$
\begin{aligned}
X= & \left(\mathrm{SR}-\mathrm{OC}-\mathrm{PC}-\mathrm{IHC}-\mathrm{BC}-\mathrm{LSC}-\mathrm{PTC}+\mathrm{IE}_{2}-\mathrm{IC}_{2}\right) \\
= & p\left[(a-b p) t_{2}+\frac{(a-b p)}{\delta}\left\{\log \left(1+\delta\left(T-t_{2}\right)\right)\right\}\right]-A \\
& -c\left[(a-b p) t_{1}+\frac{(a-b p)}{\theta m(\xi)}\left(\mathrm{e}^{\theta m(\xi)\left(t_{2}-t_{1}\right)}-1\right)+\frac{(a-b p)}{\delta}\left\{\log \left(1+\delta\left(T-t_{2}\right)\right)\right\}\right] \\
& -c_{1}\left[S t_{1}-\frac{(a-b p) t_{1}^{2}}{2}-\frac{(a-b p)}{\theta^{2} m(\xi)^{2}}\left(1-\mathrm{e}^{\theta m(\xi)\left(t_{2}-t_{1}\right)}+\theta m(\xi)\left(t_{2}-t_{1}\right)\right)\right] \\
& -c_{2}\left[\left(R+\frac{D}{\delta}\left(T-t_{2}\right)\right)-\frac{D}{\delta^{2}}\left(1+\delta\left(T-t_{2}\right)\right) \log \left(1+\delta\left(T-t_{2}\right)\right)\right] \\
& -\xi T \frac{c_{3}(a-b p)}{\delta}\left\{\delta\left(T-t_{2}\right)-\log \left(1+\delta\left(T-t_{2}\right)\right)\right\}+\frac{p I_{e}(a-b p) t_{2}^{2}}{2} \\
& +\frac{p I_{e}(a-b p) t_{2}}{\delta} \log \left(1+\delta\left(T-t_{2}\right)\right)-c I_{c}\left[\frac{(a-b p)}{(\theta m(\xi))^{2}}\left(\mathrm{e}^{\theta m(\xi)\left(t_{2}-M\right)}-1\right)+\frac{(a-b p)\left(t_{2}-M\right)}{\theta m(\xi)}\right] .
\end{aligned}
$$

Thus, the corresponding optimization problem is as follows:

Problem 3.2. $\pi^{2}(p, \xi, T)=\frac{X}{T}$, subject to constraints $t_{1}<M \leq t_{2}$.

For scenario 3 , the interest earned is measured when $t_{2}<M \leq T$ as seen in equation (3.22).

$$
\begin{aligned}
\mathrm{IE}_{3} & =p I_{e} \int_{0}^{t_{2}} \int_{0}^{t}(a-b p) \mathrm{d} u \mathrm{~d} t+\frac{p I_{e}(a-b p) t_{2}}{\delta} \log \left(1+\delta\left(T-t_{2}\right)\right) \\
& =\frac{p I_{e}(a-b p) t_{2}^{2}}{2}+\frac{p I_{e}(a-b p) t_{2}}{\delta} \log \left(1+\delta\left(T-t_{2}\right)\right) .
\end{aligned}
$$

For this case, the interest paid to the supplier is zero.

Therefore, the total profit is

$$
\pi^{3}(p, \xi, T)=\frac{X}{T},
$$


where

$$
\begin{aligned}
X= & \left(\mathrm{SR}-\mathrm{OC}-\mathrm{PC}-\mathrm{IHC}-\mathrm{BC}-\mathrm{LSC}-\mathrm{PTC}+\mathrm{IE}_{3}\right) \\
= & p\left[(a-b p) t_{2}+\frac{(a-b p)}{\delta}\left\{\log \left(1+\delta\left(T-t_{2}\right)\right)\right\}\right]-A \\
& -c\left[(a-b p) t_{1}+\frac{(a-b p)}{\theta m(\xi)}\left(\mathrm{e}^{\theta m(\xi)\left(t_{2}-t_{1}\right)}-1\right)+\frac{(a-b p)}{\delta}\left\{\log \left(1+\delta\left(T-t_{2}\right)\right)\right\}\right] \\
& -c_{1}\left[S t_{1}-\frac{(a-b p) t_{1}^{2}}{2}-\frac{(a-b p)}{\theta^{2} m(\xi)^{2}}\left(1-\mathrm{e}^{\theta m(\xi)\left(t_{2}-t_{1}\right)}+\theta m(\xi)\left(t_{2}-t_{1}\right)\right)\right] \\
& -c_{2}\left[\left(R+\frac{D}{\delta}\left(T-t_{2}\right)\right)-\frac{D}{\delta^{2}}\left(1+\delta\left(T-t_{2}\right)\right) \log \left(1+\delta\left(T-t_{2}\right)\right)\right]-\frac{c_{3}(a-b p)}{\delta}\left\{\delta\left(T-t_{2}\right)\right. \\
& \left.-\xi T+\frac{p I_{e}(a-b p) t_{2}^{2}}{2}+\frac{p I_{e}(a-b p) t_{2}}{\delta} \log \left(1+\delta\left(T-t_{2}\right)\right)\right\}
\end{aligned}
$$

Thus, the corresponding optimization problem is as follows:

Problem 3.3. $\pi^{3}(p, \xi, T)=\frac{X}{T}$, subject to constraints $t_{2}<M \leq T$.

\section{Optimal solutions AND theOREtical RESUlts}

The profit function considers sales revenue, ordering cost, holding cost, purchasing cost, backordering cost, lost sale cost, preservation technology cost, interest earned, and the interest payable. The average profit per unit time for the retailer can be expressed as:

$$
\begin{aligned}
& \pi(p, \xi, T)=\frac{1}{T}[\mathrm{SR}-\mathrm{OC}-\mathrm{PC}-\mathrm{IHC}-\mathrm{BC}-\mathrm{LSC}-\mathrm{PTC}+\mathrm{IE}-\mathrm{IP}] \\
& \pi(p, \xi, T)=\left\{\begin{array}{lll}
\pi^{1}(p, \xi, T), & \text { when } & 0<M \leq t_{1} \\
\pi^{2}(p, \xi, T), & \text { when } & t_{1}<M \leq t_{2} \\
\pi^{3}(p, \xi, T), & \text { when } & t_{2}<M \leq T
\end{array}\right.
\end{aligned}
$$

The total profit function $\pi(p, \xi, T)$ takes three branches function in which the maximum values of those three branch functions will be the required solution.

From the above expression, some continuity relations will arise given as $\pi^{1}(p, \xi, T)=\pi^{2}(p, \xi, T)$, which is continuous at point $t_{1}$ and $\pi^{2}(p, \xi, T)=\pi^{3}(p, \xi, T)$, which is continuous at point $t_{2}$.

Examining for the points $(p, \xi, T)$ directly, the maximum value of $\pi(p, \xi, T)$ is calculated by the local maximum points or the boundary points of $(p, \xi, T)$, wherein it would be bounded within the valid ranges (i.e. $0<M \leq$ $\left.t_{1}, t_{1}<M \leq t_{2}, t_{2}<M \leq T\right)$. The optimal form will be measured, $\left(p^{*}, \xi^{*}, T^{*}\right)$ such that $\pi^{*}(p, \xi, T)=$ $\max \left\{\pi^{* 1}(p, \xi, T), \pi^{* 2}(p, \xi, T), \pi^{* 3}(p, \xi, T)\right\}$.

The optimal values of $p, \xi$ and $T$ which maximize the profit function $\pi^{3}(p, \xi, T)$ for the given data set are the decision variables of the problem. The necessary conditions for maximizing the total profit function $\pi^{3}(p, \xi, T)$ can be attained by setting the first order derivatives with respect to decision variables equal to zero. Therefore, the necessary conditions are:

$$
\frac{\partial \pi^{3}(p, \xi, T)}{\partial p}=0, \frac{\partial \pi^{3}(p, \xi, T)}{\partial \xi}=0 \text { and } \frac{\partial \pi^{3}(p, \xi, T)}{\partial T}=0
$$


The first order derivatives of $\pi^{3}(p, \xi, T)$ with respect to the decision variables $p, \xi$ and $T$ are

$$
\begin{aligned}
& \frac{\partial \pi^{3}(p, \xi, T)}{\partial p}=\frac{1}{T}\left[\begin{array}{l}
(a-2 b p) t_{2}+\frac{(a-2 b p)}{\delta}\left\{\log \left(1+\delta\left(T-t_{2}\right)\right)\right\} \\
+b c\left[t_{1}+\frac{1}{\theta m(\xi)}\left(\mathrm{e}^{\theta m(\xi)\left(t_{2}-t_{1}\right)}-1\right)+\frac{1}{\delta}\left\{\log \left(1+\delta\left(T-t_{2}\right)\right)\right\}\right] \\
-c_{1}\left[\frac{1}{2} b t_{1}^{2}+\frac{b}{\theta^{2} m(\xi)^{2}}\left\{1-\mathrm{e}^{\theta m(\xi)\left(t_{2}-t_{1}\right)}+\theta m(\xi)\left(t_{2}-t_{1}\right)\right\}\right] \\
-c_{2}\left[\left(\frac{b}{\delta}\left(t_{2}-T\right)\right)+\frac{b}{\delta^{2}}\left(1+\delta\left(T-t_{2}\right)\right) \log \left(1+\delta\left(T-t_{2}\right)\right)\right] \\
+\frac{c_{3} b}{\delta}\left\{\delta\left(T-t_{2}\right)-\log \left(1+\delta\left(T-t_{2}\right)\right)\right\}-\frac{I_{e}(a-2 b p) t_{2}^{2}}{2} \\
+\frac{I_{e}(a-2 b p) t_{2}}{\delta} \log \left(1+\delta\left(T-t_{2}\right)\right)
\end{array}\right] \\
& \frac{\partial \pi^{3}(p, \xi, T)}{\partial \xi}=\frac{1}{T}\left[\begin{array}{l}
-c a_{1}(a-b p)\left[\frac{\mathrm{e}^{\theta m(\xi)\left(t_{2}-t_{1}\right)}}{\theta m(\xi)}-\mathrm{e}^{\theta m(\xi)\left(t_{2}-t_{1}\right)}\left(t_{2}-t_{1}\right)\right] \\
-c_{1} a_{1}\left[\begin{array}{l}
-\frac{2(a-b p)}{\theta^{2}} \frac{1}{m(\xi)^{2}}-\frac{(a-b p)}{\theta} \mathrm{e}^{\theta m(\xi)\left(t_{2}-t_{1}\right)}+\mathrm{e}^{\theta m(\xi)\left(t_{2}-t_{1}\right)} \frac{2}{\theta^{2}} \frac{1}{m(\xi)^{2}} \\
+\frac{(a-b p)}{\theta m(\xi)}\left(t_{2}-t_{1}\right)
\end{array}\right]-T
\end{array}\right]
\end{aligned}
$$

and

$$
\frac{\partial \pi^{3}}{\partial T}=-\frac{1}{T} \pi^{3}(p, \xi, T)+\frac{1}{T}\left[\begin{array}{l}
\frac{(p-c)(a-b p)}{1+\delta\left(T-t_{2}\right)}+\frac{c_{2}(a-b p)}{\delta} \log \left(1+\delta\left(T-t_{2}\right)\right) \\
-c_{3}(a-b p)\left[1-\frac{1}{1+\delta\left(T-t_{2}\right)}\right]+\frac{p I_{e}(a-b p) t_{2}}{1+\delta\left(T-t_{2}\right)}-\xi
\end{array}\right]
$$

Due to the high non-linearity of the profit function, the optimality of the equations could be demonstrated mathematically from the objective functions by using the following corollaries and theorems.

Corollary 4.1. The objective function $\pi^{3}(p, \xi, T)$ is maximum with respect to $T$ when the decision variable $p$ and $\xi$ are fixed and when $\frac{1}{T} \frac{\partial^{2} X}{\partial T^{2}}+\frac{2 X}{T^{3}}<\frac{2}{T^{2}} \frac{\partial X}{\partial T}$ (Appendix B).

Corollary 4.2. The objective function $\pi^{3}(p, \xi, T)$ is maximum with respect to $p$ when the decision variable $T$ and $\xi$ are fixed and when $\frac{\delta I_{e} t_{2}\left(t_{2}-4\right)}{2 I_{e} t_{2}+4}<\log \left(1+\delta\left(T-t_{2}\right)\right)$ (Appendix B).

To prove concavity, we use the theorems from Cambini and Martein [4] which is also used by Dye [6].

Lemma 4.3. If $\phi_{1}(x)$ is non-negative, differentiable and (strictly) concave, and $\phi_{2}(x)$ is positive, differentiable and convex, then the real-value function $\chi(x)=\frac{\phi_{1}(x)}{\phi_{2}(x)}, x \in \mathrm{R}$ is (strictly) pseudo-concave.

Proof. See Cambini and Martein ([4], p. 245) for details.

For any given $p$ and $T$, applying Lemma 4.3, it could easily prove that the total profit $\pi^{3}(p, \xi, T)$ is strictly pseudo-concave in $\xi$. As a result, for any given $p$ and $T$, there exists a unique global optimal solution $\xi^{*}$ such that $\pi^{3}(p, \xi, T)$ is maximized.

Theorem 4.4. The value of the objective function $\pi^{3}(p, \xi, T)$ attains its global maximum with respect to $\xi$ when other parameters are fixed. 
Proof. We define the profit function as

$$
\phi_{1}(\xi)=\left[\begin{array}{l}
p\left[(a-b p) t_{2}+\frac{(a-b p)}{\delta}\left\{\log \left(1+\delta\left(T-t_{2}\right)\right)\right\}\right]-A \\
-c\left[(a-b p) t_{1}+\frac{(a-b p)}{\theta m(\xi)}\left(\mathrm{e}^{\theta m(\xi)\left(t_{2}-t_{1}\right)}-1\right)+\frac{(a-b p)}{\delta}\left\{\log \left(1+\delta\left(T-t_{2}\right)\right)\right\}\right] \\
-c_{1}\left[S t_{1}-\frac{(a-b p) t_{1}^{2}}{2}-\frac{(a-b p)}{\theta^{2} m(\xi)^{2}}\left(1-\mathrm{e}^{\theta m(\xi)\left(t_{2}-t_{1}\right)}+\theta m(\xi)\left(t_{2}-t_{1}\right)\right)\right] \\
-c_{2}\left[\left(R+\frac{D}{\delta}\left(T-t_{2}\right)\right)-\frac{D}{\delta^{2}}\left(1+\delta\left(T-t_{2}\right)\right) \log \left(1+\delta\left(T-t_{2}\right)\right)\right]-\frac{c_{3}(a-b p)}{\delta}\left\{\begin{array}{l}
\delta\left(T-t_{2}\right)- \\
\log \left(1+\delta\left(T-t_{2}\right)\right)
\end{array}\right\} \\
-\xi T+\frac{p I_{e}(a-b p) t_{2}^{2}}{2}+\frac{p I_{e}(a-b p) t_{2}}{\delta} \log \left(1+\delta\left(T-t_{2}\right)\right)
\end{array}\right]
$$

and $\phi_{2}(\xi)=T>0$.

From the above equation, it is clear that $\phi_{2}(\xi)$ is non-negative, differentiable and (strictly) concave. We only need to proof that $\phi_{1}(\xi)$ is positive, differentiable and convex. For any fixed $p$ and $T$, the second order derivative of the objective function $\pi^{3}(p, \xi, T)$ with respect to the decision variables $\xi$ is

$$
\phi_{1}^{\prime}(\xi)=\left[\begin{array}{l}
-c(a-b p)\left[\mathrm{e}^{\theta m(\xi)\left(t_{2}-t_{1}\right)} \cdot \frac{a_{1} \mathrm{e}^{-a_{1} \xi}}{\theta m(\xi)^{2}}-\frac{a_{1} \mathrm{e}^{-a_{1} \xi}}{\theta m(\xi)} \cdot \mathrm{e}^{\theta m(\xi)\left(t_{2}-t_{1}\right)} \theta\left(t_{2}-t_{1}\right)\right] \\
-c_{1}\left[\begin{array}{l}
-\frac{2 a_{1} \mathrm{e}^{-a_{1} \xi}(a-b p)}{\theta^{2}} \frac{1}{m(\xi)^{3}}-\frac{(a-b p) a_{1} \mathrm{e}^{-a_{1} \xi}}{\theta m(\xi)} \mathrm{e}^{\theta m(\xi)\left(t_{2}-t_{1}\right)} \\
+\mathrm{e}^{\theta m(\xi)\left(t_{2}-t_{1}\right)} \frac{2}{\theta^{2}} \frac{a_{1} \mathrm{e}^{-a_{1} \xi}}{m(\xi)^{3}}+\frac{(a-b p) a_{1} \mathrm{e}^{-a_{1} \xi}}{\theta m(\xi)^{2}}\left(t_{2}-t_{1}\right)
\end{array}\right]-T
\end{array}\right] .
$$

Using the necessary condition $\frac{\partial \pi^{3}(p, \xi, T)}{\partial \xi}=0$, equation (4.8) becomes

$$
\begin{aligned}
& \phi_{2}^{\prime \prime}(\xi)= {\left[\begin{array}{l}
c(a-b p) a_{1}^{2} \mathrm{e}^{\theta m(\xi)\left(t_{2}-t_{1}\right)}\left(t_{2}-t_{1}\right)\left[1-\theta\left(t_{2}-t_{1}\right) \mathrm{e}^{-a_{1} \xi}\right]-c(a-b p) a_{1} \frac{\mathrm{e}^{\theta m(\xi)\left(t_{2}-t_{1}\right)}}{\theta m(\xi)^{2}} \\
-c_{1} a_{1}^{2}\left[\begin{array}{l}
-\frac{4(a-b p)}{\theta^{2}} \frac{1}{m(\xi)^{2}}+(a-b p) \mathrm{e}^{\theta m(\xi)\left(t_{2}-t_{1}\right)}\left(t_{2}-t_{1}\right) \mathrm{e}^{-a_{1} \xi}+\frac{4}{\theta^{2}} \mathrm{e}^{\theta m(\xi)\left(t_{2}-t_{1}\right)} \frac{1}{m(\xi)^{2}} \\
+\frac{2}{\theta} \frac{1}{m(\xi)} \mathrm{e}^{\theta m(\xi)\left(t_{2}-t_{1}\right)}\left(t_{2}-t_{1}\right)+(a-b p)\left(t_{2}-t_{1}\right) \frac{1}{\theta m(\xi)}
\end{array}\right]
\end{array}\right] } \\
& \phi_{2}^{\prime \prime}(\xi)=\left[\begin{array}{l}
c a_{1}^{2}(a-b p) \mathrm{e}^{\theta m(\xi)\left(t_{2}-t_{1}\right)}\left(t_{2}-t_{1}\right)\left[1-\mathrm{e}^{-a_{1} \xi}\left(1+\theta\left(t_{2}-t_{1}\right)\right)\right]-c(a-b p) a_{1} \frac{\mathrm{e}^{\theta m(\xi)\left(t_{2}-t_{1}\right)}}{\theta m(\xi)^{2}} \\
-c_{1} a_{1}^{2}\left[\frac{4}{\theta^{2}} \frac{1}{m(\xi)^{2}}\left(\mathrm{e}^{\theta m(\xi)\left(t_{2}-t_{1}\right)}-(a-b p)\right)+\frac{1}{\theta} \frac{1}{m(\xi)}\left(t_{2}-t_{1}\right)\left(2 \mathrm{e}^{\theta m(\xi)\left(t_{2}-t_{1}\right)}+a-b p\right)\right]
\end{array}\right] .
\end{aligned}
$$

Now we need to prove $\phi_{2}^{\prime \prime}(\xi)$ is less than zero:

$$
\left[\begin{array}{l}
c a_{1}^{2}(a-b p) \mathrm{e}^{\theta m(\xi)\left(t_{2}-t_{1}\right)}\left(t_{2}-t_{1}\right)\left[1-\mathrm{e}^{-a_{1} \xi}\left(1+\theta\left(t_{2}-t_{1}\right)\right)\right]-c(a-b p) a_{1} \frac{\mathrm{e}^{\theta m(\xi)\left(t_{2}-t_{1}\right)}}{\theta m(\xi)^{2}} \\
-c_{1} a_{1}^{2}\left[\frac{4}{\theta^{2}} \frac{1}{m(\xi)^{2}}\left(\mathrm{e}^{\theta m(\xi)\left(t_{2}-t_{1}\right)}-(a-b p)\right)+\frac{1}{\theta} \frac{1}{m(\xi)}\left(t_{2}-t_{1}\right)\left(2 \mathrm{e}^{\theta m(\xi)\left(t_{2}-t_{1}\right)}+a-b p\right)\right]
\end{array}\right]<0 .
$$

This means,

$$
\begin{aligned}
\Rightarrow & {\left[c a_{1}^{2}(a-b p) \mathrm{e}^{\theta m(\xi)\left(t_{2}-t_{1}\right)}\left(t_{2}-t_{1}\right)\left[1-\mathrm{e}^{-a_{1} \xi}\left(1+\theta\left(t_{2}-t_{1}\right)\right)\right]\right]<c(a-b p) a_{1} \frac{\mathrm{e}^{\theta m(\xi)\left(t_{2}-t_{1}\right)}}{\theta m(\xi)^{2}} } \\
& +c_{1} a_{1}^{2}\left[\frac{4}{\theta^{2}} \frac{1}{m(\xi)^{2}}\left(\mathrm{e}^{\theta m(\xi)\left(t_{2}-t_{1}\right)}-(a-b p)\right)+\frac{1}{\theta} \frac{1}{m(\xi)}\left(t_{2}-t_{1}\right)\left(2 \mathrm{e}^{\theta m(\xi)\left(t_{2}-t_{1}\right)}+a-b p\right)\right] \\
\Rightarrow & a_{1}\left(t_{2}-t_{1}\right) \theta(a-b p) m(\xi)^{2} \mathrm{e}^{\theta m(\xi)\left(t_{2}-t_{1}\right)}\left[1-m(\xi)\left[1+\theta\left(t_{2}-t_{1}\right)\right]\right] \\
& <\left[\mathrm{e}^{\theta m(\xi)\left(t_{2}-t_{1}\right)}\left[(a-b p)+\frac{4 a_{1}}{\theta}\right]+m(\xi)\left(t_{2}-t_{1}\right)\left[(a-b p)+2 \mathrm{e}^{\theta m(\xi)\left(t_{2}-t_{1}\right)}\right]\right] .
\end{aligned}
$$


To prove that $\left[(a-b p)+\frac{4 a_{1}}{\theta}\right]$ and $\left[(a-b p)+2 \mathrm{e}^{\theta m(\xi)\left(t_{2}-t_{1}\right)}\right]$ are greater than zero, consider that demand is always positive and that deterioration lies between 0 to 1 , the right-hand side of the equation mentioned above will satisfy the equation above. From the equation, the right-hand side is greater than zero. If the left side is less than zero, it satisfies the condition. That is

$$
a_{1}\left(t_{2}-t_{1}\right) \theta(a-b p) m(\xi)^{2} \mathrm{e}^{\theta m(\xi)\left(t_{2}-t_{1}\right)}\left[1-m(\xi)\left[1+\theta\left(t_{2}-t_{1}\right)\right]\right]<0 .
$$

Moreover, $\left[1-m(\xi)\left[1+\theta\left(t_{2}-t_{1}\right)\right]\right]<0$ as $\left(t_{2}-t_{1}\right) \geq 0$ and the deterioration is positive, the value of $\theta\left(t_{2}-t_{1}\right)$ is also positive. It could be written as $\left[1-m(\xi)\left[1+k_{1}\right]\right]<0$. One can deduce that $\left[1-m(\xi) k_{2}\right]<0$, since $\left[1+k_{1}\right]=k_{2}$. The deterioration rate $m(\xi)$ with the investment of preservation technology and having the original deterioration from 0 to 1 , the value of $m(\xi) k_{2}$ is then positive. Therefore, $a_{1}\left(t_{2}-t_{1}\right) \theta(a-$ $b p) m(\xi)^{2} \mathrm{e}^{\theta m(\xi)\left(t_{2}-t_{1}\right)}\left[1-m(\xi)\left[1+\theta\left(t_{2}-t_{1}\right)\right]\right]<0$; thus completing the proof.

Theorem 4.5. The value of the objective function $\pi^{3}(p, \xi, T)$ attains its global maximum with respect to $p$ when other parameters are fixed.

Proof. The proof is omitted because it is similar to the proof of Theorem 4.4.

Theorem 4.6. The value of the objective function $\pi^{3}(p, \xi, T)$ attains its global maximum with respect to $T$ when other parameters are fixed.

Proof. The proof is omitted because it is similar to the proof of Theorem 4.4.

Theorem 4.7. The value of the objective function $\pi^{3}(p, \xi, T)$ attains its global maximum with respect to $p$ and $T$ when other parameters are fixed and hence there exists a unique maximum solution at $\left(p^{*}, T^{*}\right)$.

Proof. For convenience, let us define the profit function as

$$
\begin{aligned}
& \phi_{1}(p, T)=\left[\begin{array}{l}
p\left[(a-b p) t_{2}+\frac{(a-b p)}{\delta}\left\{\log \left(1+\delta\left(T-t_{2}\right)\right)\right\}\right]-A \\
-c\left[(a-b p) t_{1}+\frac{(a-b p)}{\theta m(\xi)}\left(\mathrm{e}^{\theta m(\xi)\left(t_{2}-t_{1}\right)}-1\right)+\frac{(a-b p)}{\delta}\left\{\log \left(1+\delta\left(T-t_{2}\right)\right)\right\}\right] \\
-c_{1}\left[S t_{1}-\frac{(a-b p) t_{1}^{2}}{2}-\frac{(a-b p)}{\theta^{2} m(\xi)^{2}}\left(1-\mathrm{e}^{\theta m(\xi)\left(t_{2}-t_{1}\right)}+\theta m(\xi)\left(t_{2}-t_{1}\right)\right)\right] \\
-c_{2}\left[\left(R+\frac{D}{\delta}\left(T-t_{2}\right)\right)-\frac{D}{\delta^{2}}\left(1+\delta\left(T-t_{2}\right)\right) \log \left(1+\delta\left(T-t_{2}\right)\right)\right]-\frac{c_{3}(a-b p)}{\delta}\left\{\begin{array}{l}
\delta\left(T-t_{2}\right) \\
-\log \left(1+\delta\left(T-t_{2}\right)\right)
\end{array}\right\} \\
-\xi T+\frac{p I_{e}(a-b p) t_{2}^{2}}{2}+\frac{p I_{e}(a-b p) t_{2}}{\delta} \log \left(1+\delta\left(T-t_{2}\right)\right)
\end{array}\right] \\
& \text { and } \phi_{2}(p, T)=T>0 .
\end{aligned}
$$

From the results in Cambini and Martein ([4], p. 245), we prove that $\phi_{1}(p, T)$ is a differentiable, negative and strictly joint concave function with respect to the decision variables $p$ and $T$. To generate the Hessian matrix for the function $f_{1}(P, T)$, we calculate all the second-order partial derivatives with respect to the decision variables $p$ and $T$ with a Hessian matrix for the function $\phi_{1}(p, T)$

$$
\begin{aligned}
\frac{\partial^{2} \phi_{1}(p, T)}{\partial p^{2}}= & -\left[2 b t_{2}+\frac{2 b}{\delta}\left\{\log \left(1+\delta\left(T-t_{2}\right)\right)\right\}-\frac{I_{e} b t_{2}^{2}}{2}+\frac{I_{e} b t_{2}}{\delta} \log \left(1+\delta\left(T-t_{2}\right)\right)\right] \\
\frac{\partial^{2} \phi_{1}(p, T)}{\partial T^{2}}= & -\frac{D}{\left(1+\delta\left(T-t_{2}\right)\right)^{2}}\left[\delta(p-c)+c_{2} \delta+c_{2}\left(1+\delta\left(T-t_{2}\right)\right)+c_{3} \delta+p \delta I_{e} t_{2}\right] \\
\frac{\partial^{2} \phi_{1}(p, T)}{\partial p \partial T}= & {\left[\frac{b}{\delta}\left(1+\log \left(1+\delta\left(T-t_{2}\right)\right)+c_{2}\right)+\frac{1}{\left(1+\delta\left(T-t_{2}\right)\right)}\left(c_{2} b+b(c-p)+c_{3} b \delta\left(T-t_{2}\right)\right)\right.} \\
& \left.+I_{e} D t_{2}-p b I_{e} t_{2}\right] .
\end{aligned}
$$


Therefore, the Hessian matrix for the function $\phi_{1}(p, T)$ is

$$
H_{i j}=\left[\begin{array}{cc}
\frac{\partial^{2} \phi_{1}}{\partial p^{2}} & \frac{\partial^{2} \phi_{1}}{\partial p \partial T} \\
\frac{\partial^{2} \phi_{1}}{\partial T \partial p} & \frac{\partial^{2} \phi_{1}}{\partial T^{2}}
\end{array}\right] .
$$

Now, considering the first principal minor:

$$
\left|H_{11}\right|=\frac{\partial^{2} \phi_{1}(p, T)}{\partial p^{2}}=-\left[2 b t_{2}+\frac{2 b}{\delta}\left\{\log \left(1+\delta\left(T-t_{2}\right)\right)\right\}-\frac{I_{e} b t_{2}^{2}}{2}+\frac{I_{e} b t_{2}}{\delta} \log \left(1+\delta\left(T-t_{2}\right)\right)\right] .
$$

It is clearly seen that the above $\left|H_{11}\right|$ is less than zero.

Then, to calculate Hessian matrix $H_{i j}$ we need to check the second principal minor

$$
\begin{aligned}
& \left|H_{22}\right|=\frac{\partial^{2} \phi_{1}(p, T)}{\partial p^{2}} \frac{\partial^{2} \phi_{1}(p, T)}{\partial T^{2}}-\frac{\partial^{2} \phi_{1}(p, T)}{\partial p \partial T} \\
& =\left(2 b t_{2}+\frac{2 b}{\delta}\left\{\log \left(1+\delta\left(T-t_{2}\right)\right)\right\}-\frac{I_{e} b t_{2}^{2}}{2}+\frac{I_{e} b t_{2}}{\delta} \log \left(1+\delta\left(T-t_{2}\right)\right) * \frac{D}{\left(1+\delta\left(T-t_{2}\right)\right)^{2}}(\delta(p-c)\right. \\
& \left.\left.+c_{2} \delta+c_{2}\left(1+\delta\left(T-t_{2}\right)\right)+c_{3} \delta+p \delta I_{e} t_{2}\right)\right)-\left[\frac{b}{\delta}\left(1+\log \left(1+\delta\left(T-t_{2}\right)\right)+c_{2}\right)\right. \\
& \left.\left.+\frac{1}{\left(1+\delta\left(T-t_{2}\right)\right)}\left(c_{2} b+b(c-p)+c_{3} b \delta\left(T-t_{2}\right)\right)+I_{e} D t_{2}-p b I_{e} t_{2}\right)\right]
\end{aligned}
$$

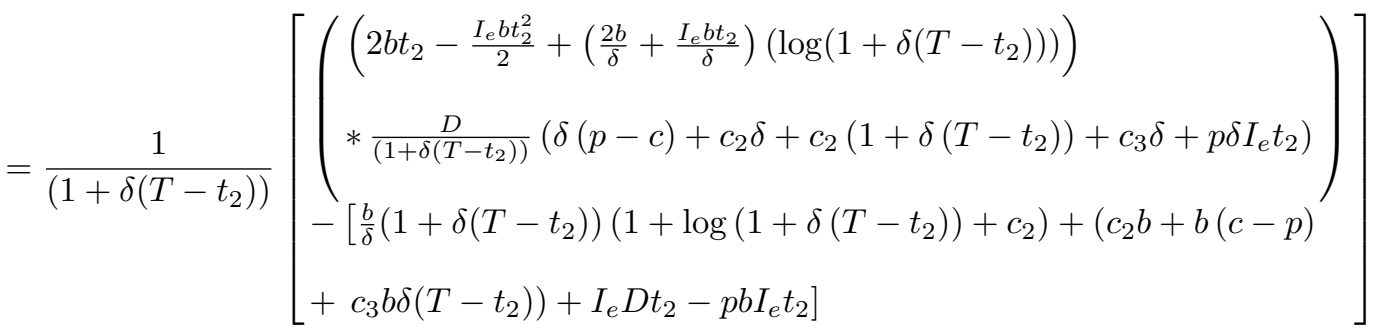

Since the lost sale cost is greater than the purchase cost of the products, one can conclude from the above equation that without loss of generality the principal minor $\left|H_{22}\right|$ is always less than zero.

It is seen from the above manipulation that first principle minor is negative and second one is positive so the Hessian matrix for $\phi_{1}(p, T)$ are negative, so the Hessian matrix is also treat as negative definite matrix. Therefore, one can conclude that the function $\phi_{1}(p, T)$ is differentiable, and (strictly) concave function with respect to the decision variables $p$ and $T$. Likewise, the total profit function per unit time $\pi^{3}(p, \xi, T)$ is pseudoconcave with respect to decision variables $p$ and $T$. Consequently, the objective function $\pi^{3}(p, \xi, T)$ attains its global maximum value at the point $\left(p^{*}, T^{*}\right)$.

Theorem 4.8. The value of the objective function $\pi^{3}(p, \xi, T)$ attains its global maximum with respect to $p$ and $\xi$ when other parameters are fixed and hence there exists a unique maximum solution at $\left(p^{*}, \xi^{*}\right)$.

Proof. The proof is omitted because it is similar to the proof of Theorem 4.7

Theorem 4.9. The value of the objective function $\pi^{3}(p, \xi, T)$ attains its global maximum with respect to $\xi$ and $T$ when other parameters are fixed and hence there exists a unique maximum solution at $\left(\xi^{*}, T^{*}\right)$.

Proof. The proof is omitted because it is similar to the proof of Theorem 4.7 


\section{Special CASES OF THE PROPOSED MODEL}

(i) When $\delta \rightarrow \infty$ (i.e. no shortages) then the proposed model here will become an EOQ model with no shortages.

(ii) For the non-deterioration period $t_{1}=0$ with $t_{2}=0$ and $\delta \rightarrow \infty$, then the model is reduced to the instantaneous EOQ model of Mishra et al. [18].

(iii) If $\delta \rightarrow 0$ then the proposed model will be reduce to an EOQ model of fully backlogged shortages.

(iv) Taking into account $t_{2}=T$ and $\delta \rightarrow \infty$, then the model becomes that of Zhang et al. [36], an instantaneous deterioration with no shortages.

(v) If $t_{1}=0$ and $b=0$ (i.e. demand function is constant), then the proposed model is reduced to the model of Dye and Hsieh [7].

\section{FlowChart FOR THE SOLUTION SYSTEM}

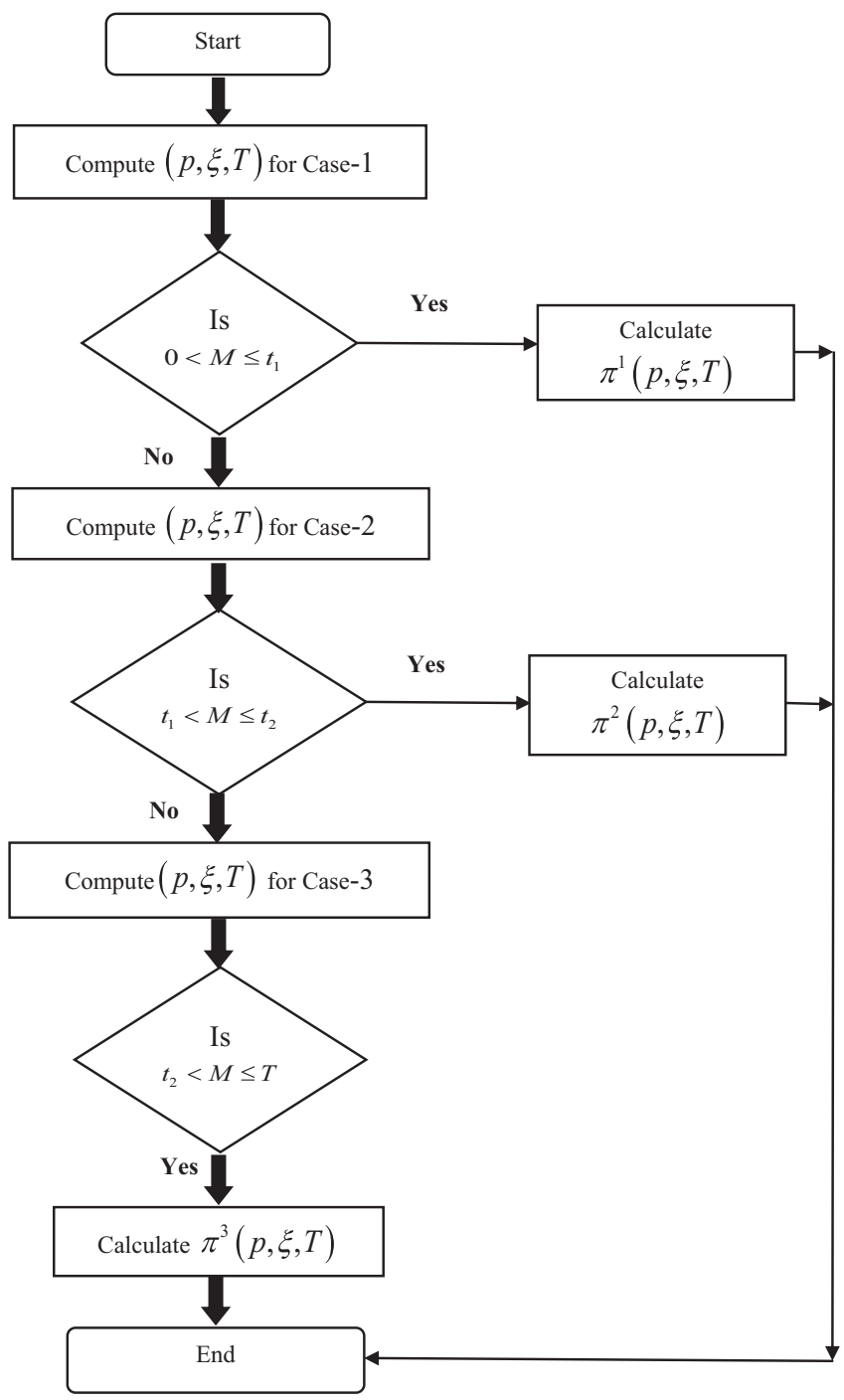

Figure 2. Flowchart of the solution system. 


\section{NumERICAL EXAMPLES}

The solution of the proposed inventory model is discussed in this part, specifically deteriorating products like vegetables, fruit, sweets, etc. This is because in any season, the demand for this item increases linearly depending on the selling price. Initially, no deterioration in the initial stage is considered as the items are of high quality. After some time, deterioration begins, and the stocks deplete. To demonstrate the inventory model, three numerical examples are given with different parameters as shown:

\section{Example 1}

Given: ordering cost is $\mathrm{OC}=\$ 1500$ per order, $a=300 ; b=5$, holding cost rates for inventory of different items $C_{1}=\$ 5$, backorder cost rate for inventory $C_{2}=\$ 5$, lost sale cost for the inventory $C_{3}=\$ 27$, purchase cost of different item $C=\$ 8, a_{1}=\$ 0.8$ per unit, deterioration rate $\theta=0.5$, backlogging parameter for the inventory is $\delta=1.5$, time after deterioration will start for the inventory $t_{1}=0.3$, percentage of interest charged $I_{c}=\$ 0.06$ percentage of interest earned $I_{e}=\$ 0.12$, and permissible delay period from supplier to retailers is $M=0.1 \mathrm{yr}$.

\section{Example 2}

Given: Similar to example 1, the permissible delay period from the supplier to the retailers is $M=0.8 \mathrm{yr}$ instead of $0.1 \mathrm{yr}$.

\section{Example 3}

Given: Similar to example 1, the permissible delay period from the supplier to the retailers is $M=2.5 \mathrm{yr}$ instead of $0.1 \mathrm{yr}$ (Tab. 3).

Therefore, a unique optimal solution is illustrated in Figures 3-5, showing that the profit function is concave.

To clarify the graph of "Total profit" vs. $P$ vs. T, a two-dimensional graph of "Total profit" vs. $P$ and "Total profit" vs. $T$ is provided as seen in Figures 6 and 7.

\section{Example 4}

In this example, consider the same parametric values for the inventory model of Dye and Hsieh [7] given that:

$$
\begin{aligned}
& c_{2}=\$ 4 / \text { per order; } \mathrm{c}=\$ 20 / \text { per order; OC }=\$ 120 / \text { per order; } \mathrm{p}=\$ 35 / \text { per order; } \mathrm{c}_{1}=\$ 3 / \text { per order; } \\
& D=1000 ; c_{3}=\$ 5 / \text { perorder; } \mathrm{t}_{1}=0 ; \delta=2 ; \mathrm{a}_{1}=0.01
\end{aligned}
$$

and if one assumes that the trade credit period $M=0$ and the interest earn is $I_{e}=0$, the example is identical with that of Dye and Hsieh [7], but shows an optimal value is $\$ 11908.4$ compared with Dye's $\$ 13919.3$.

However, the trade credit period and interest earned should be: $M=3.2 ; I e=0.06$;

Therefore, the optimal solution is $T^{*}=3.522897, p^{*}=35, \xi^{*}=89.16101, \Pi^{*}\left(p^{*}, \xi^{*}, T^{*}\right)=14076.86$, and the values of $M$ to satisfy the condition must be $t_{2}<M \leq T$.

TABLE 3. Results for each case of the inventory model.

\begin{tabular}{llllllll}
\hline \hline \multirow{2}{*}{ Examples } & \multicolumn{7}{c}{ Results } \\
\cline { 2 - 8 } & Condition & $S$ & $R$ & $p$ & $\xi$ & $T$ & $\pi^{2}(p, \xi, T)$ \\
\hline \multirow{2}{*}{1} & $0<M \leq t_{1}$ & 170.067 & 29.664 & 39.952 & 0.367 & 1.796 & 1184.30 \\
2 & $t_{1}<M \leq t_{2}$ & 94.304 & 32.355 & 37.913 & 0.269 & 1.167 & 1066.879 \\
3 & $t_{2}<M \leq T$ & 258.123 & 32.648 & 40.963 & 0.453 & 2.50 & 1255.818 \\
\hline
\end{tabular}




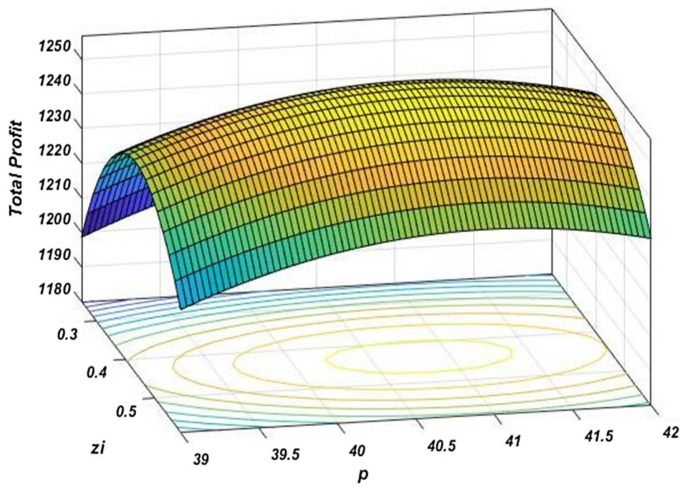

FiguRE 3. Total profit function with respect to $p$ and $z i$.

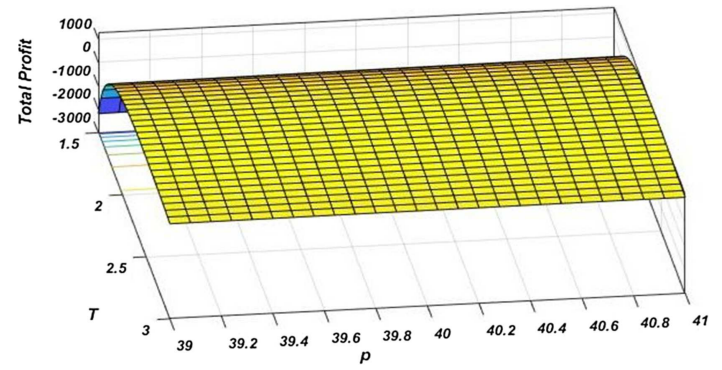

Figure 4. Total profit with respect to $p$ and $T$.

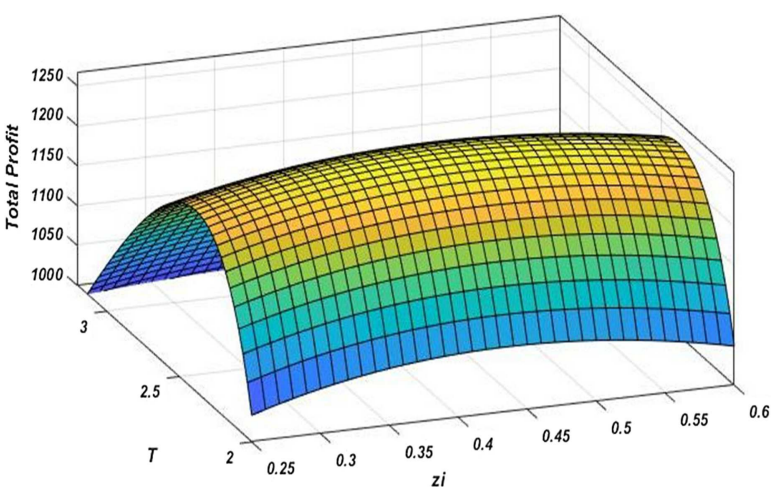

Figure 5. Total profit function with respect to $T$ and $z i$.

\section{Observation}

It is noted that when the interest earned is zero, the total profit is decreasing with the increase of trade credit policy. Similarly, it happens when interest earned is $I_{e}=0.06$ and 0.08 .

From Table 4, it is seen that with the increase of trade credit period, the total cycle length will also increase. Therefore, the retailer consequently needs to preserve products over that time. As a result, the retailer needs to invest more money in preservation technology, which will decrease his total profit. It also noted that after a certain period the facility of trade credit policy would become a burden for the retailer. 


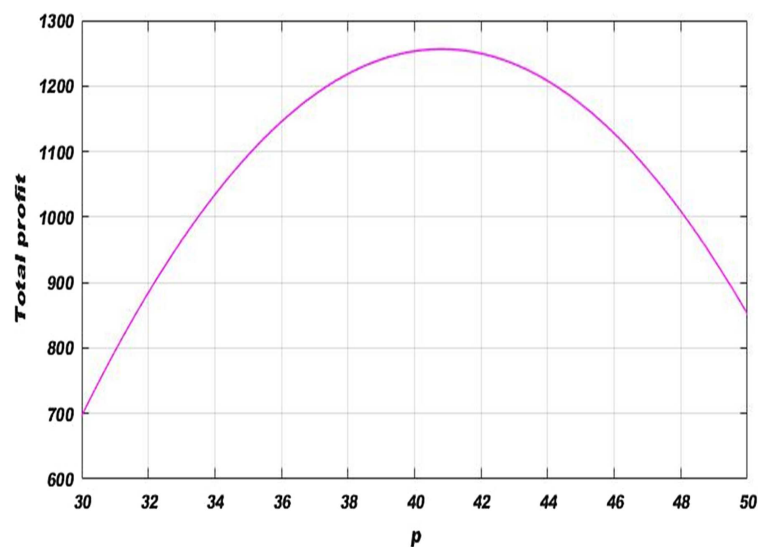

FiguRE 6. Total profit with $p$.

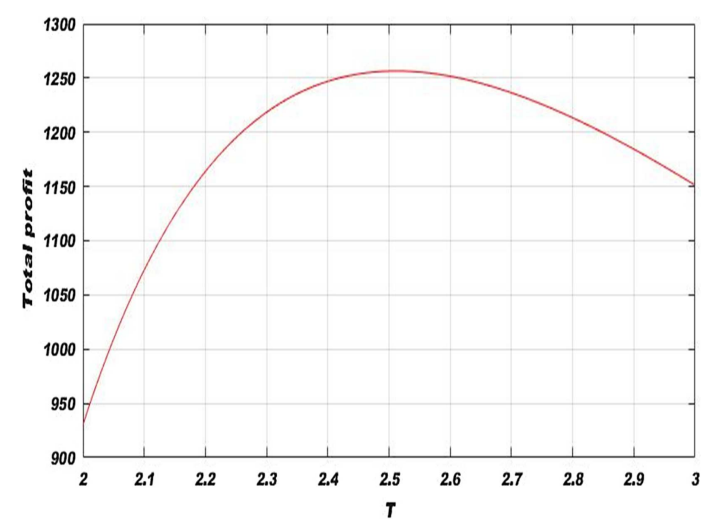

FIgURE 7. Total profit with $T$.

\section{Example 5}

In this example, we consider the same parametric values for the inventory system of Zhang et al. [36], given $\mathrm{OC}=k=\$ 80 /$ per order $; a=\alpha=100 ; b=\beta=5 ; c_{1}=h=\$ 1 /$ per order; $a_{1}=\gamma=0.05 ; c=\$ 5 /$ per order; $\theta=$ 0.5 with the trade credit period $M=0$ and Interest earn $I e=0$.

The optimal solution is $T^{*}=1.585916, p^{*}=13.22326, \xi^{*}=12.19286, \pi^{*}\left(p^{*}, \xi^{*}, T^{*}\right)=166.7125$. While the value of Zhang et al. [36] is 153.8268 (Tab. 5).

\section{Observation}

When the values of interest earned are $I_{e}=0,0.06,0.08$, it could be readily observed that with the increase of trade credit period $M$ the total profit would decrease. Like the trade, credit period and selling price increased. This shows that the retailer would want to sell more products to increase the profit. However, with the increase of total cycle length, the retailer needs more time to preserve products which will cost more money in the investments of preservation technology in order to fully preserve the products.

\section{For different types of deterioration, the following were considered}

Case 1 Considering the Weibull distribution deterioration rate. 
TABLE 4. Computational values for different $M$ and $I e$.

\begin{tabular}{lllllll}
\hline \hline$M$ & $I_{e}$ & $t_{2}<M \leq T$ & $p^{*}$ & $\xi^{*}$ & $T^{*}$ & $\pi^{*}$ \\
\hline \multirow{2}{2}{.5} & 0 & No & 35.00 & 73.62892 & 2.532359 & 11162.31 \\
& 0.06 & No & 35.00 & 79.20355 & 2.891557 & 13885.10 \\
& 0.08 & No & 35.00 & 79.22611 & 2.894031 & 14816.65 \\
\hline 3.2 & 0 & Yes & 35.00 & 83.20161 & 3.200000 & 10958.48 \\
& 0.06 & Yes & 35.00 & 89.16101 & 3.522897 & 14076.86 \\
& 0.08 & Yes & 35.00 & 90.71324 & 3.621504 & 15251.42 \\
\hline 4.5 & 0 & Yes & 35.00 & 100.1261 & 4.50000 & 9769.280 \\
& 0.06 & Yes & 35.00 & 103.4082 & 4.50000 & 13755.44 \\
& 0.08 & Yes & 35.00 & 104.1227 & 4.50000 & 15177.86 \\
\hline 26 & 0 & Yes & 35.00 & - & - & Non-optimal \\
& 0.06 & Yes & 35.00 & 244.0023 & 26.0000 & 116.7840 \\
& 0.08 & Yes & 35.00 & 255.4683 & 26.0000 & 1060.789 \\
\hline & & & & & & \\
\hline
\end{tabular}

TABLE 5. Computational values for different $M$ and $I_{e}$.

\begin{tabular}{llllll}
\hline \hline$M$ & $I_{e}$ & $p^{*}$ & $\xi^{*}$ & $T^{*}$ & $\pi^{*}$ \\
\hline 0 & 0 & 13.22326 & 12.19286 & 1.585916 & 166.7125 \\
\hline 2.5 & 0 & 13.65001 & 13.60593 & 2.500000 & 155.7524 \\
& 0.06 & 13.39491 & 13.63798 & 2.500000 & 188.6056 \\
& 0.08 & 13.31763 & 13.64722 & 2.500000 & 199.6978 \\
\hline 3 & 0 & 13.89860 & 14.37439 & 3.000000 & 144.8509 \\
& 0.06 & 13.57610 & 14.41559 & 3.000000 & 183.5771 \\
& 0.08 & 13.48015 & 14.42709 & 3.000000 & 196.7103 \\
\hline
\end{tabular}

Taking all the values (same as that of Example 3), except the deterioration rate, the Weibull distribution deterioration is suitable to be used when there is a minimal life, $t_{1}(>0)$. Considering a deterioration-free period offered in the model, the details of which are available from the study of Begum et al. [2]. Taking the same Weibull distribution deterioration rate of Shah et al. [27], $\theta(t)=\alpha \beta(t-\gamma)^{\beta-1}$, but having the deterioration free time to be $\left(\gamma=t_{1}\right), \alpha$ and $\beta$ are 0.04 and 2.4 , respectively and $\gamma$ is 0.3 , the optimal solution is

$$
T^{*}=3.349560, p^{*}=42.56130, \xi^{*}=0.4622905, \pi^{*}\left(p^{*}, \xi^{*}, T^{*}\right)=1056.650 .
$$

The following managerial insights would be obtained from the results (Tab. 6).

\section{Observation 1}

When the values of $\alpha$ and $\beta$ are fixed, the profit increases with the increase of the non-deterioration period. It is also observed that when the retailer gets more time to sell his products with a lower rate, the products would get better profit due to lower deterioration period. This is because as the non-deterioration period increased then the retailer does not need to invest more money in preservation technology to reduce deterioration.

\section{Observation 2}

When the values of $\alpha$ is fixed, increasing $\beta$ and the non-deterioration period $t_{1}$ will increase the total profit. However, the total cycle time, as well as the selling price of the products will decrease with the increase of non-deterioration period together with $\beta$. 
TABLE 6. Computational results for different values of $\alpha$ and $\beta$ for fixed $M=3.2$.

\begin{tabular}{lllllll}
\hline \hline$\alpha$ & $\beta$ & $t_{1}$ & $p^{*}$ & $\xi^{*}$ & $T^{*}$ & $\pi^{*}$ \\
\hline 0.04 & 2.4 & 0.1 & 43.11616 & 0.7700489 & 3.868266 & 1083.132 \\
& & 0.3 & 42.96688 & 0.7057555 & 3.875276 & 1109.910 \\
& & 0.5 & 42.78921 & 0.6386975 & 3.886757 & 1142.537 \\
\hline 0.04 & 2.6 & 0.1 & 42.04866 & 0.9092852 & 3.592346 & 1249.924 \\
& & 0.3 & 41.96194 & 0.8412425 & 3.622224 & 1270.096 \\
& & 0.5 & 41.84539 & 0.7709814 & 3.658458 & 1296.912 \\
\hline 0.06 & 2.4 & 0.1 & 41.72899 & 0.8850493 & 3.411081 & 1288.146 \\
& & 0.3 & 41.61300 & 0.8155702 & 3.427674 & 1312.834 \\
& & 0.5 & 41.46695 & 0.7430020 & 3.449885 & 1344.411 \\
\hline 0.06 & 2.6 & 0.1 & 40.86074 & 1.022808 & 3.200147 & 1430.049 \\
& & 0.3 & 40.80553 & 0.9492549 & 3.236880 & 1447.581 \\
& & 0.5 & 40.71807 & 0.8731135 & 3.280793 & 1472.921 \\
\hline
\end{tabular}

Case 2 Considering variable deterioration rate.

Taking all the values (same as that of Example 3), except the deterioration rate; also taking the same time varying deterioration rate of Dye and Hsieh [7] as $\theta(t)=0.2+0.1 t$, and adapting it to the model shows that the optimal solution is $T^{*}=3.00, p^{*}=41.86581, \xi^{*}=0.5119012, \pi^{*}\left(p^{*}, \xi^{*}, T^{*}\right)=1190.987$.

\section{SEnsitivity ANALYSiS}

Sensitivity analysis was executed on the optimal result for the given data set (example 3 from the numerical example) in order to study the influence of under or overestimation of the inventory system factors on the optimal values of the cycle length $\left(T^{*}\right)$, preservation cost $\left(\xi^{*}\right)$, selling price $\left(p^{*}\right)$, initial stock $\left(S^{*}\right)$, maximum shortage $(R *)$, along with the maximum profit $\left(\pi^{*}\right)$ of the system. The percentage variations in the aforementioned optimal values were taken as processes of sensitivity. The analysis was carried out by changing the key parameters from $-20 \%$ to $+20 \%$, one parameter at a time and keeping all other parameter fixed, the result shown in Table 7 .

From Table 7, the following observations were found.

\section{Observations 1}

When the value of the parameters $b, c_{p}, c_{1}, c_{2}, c_{3}, \delta, M$, decreases and the value of the parameters $a, \theta, t_{1}, I_{e}$ increases, the optimum total profit function $\pi^{*}$ decreases. It is observed that when the replenishment cost per order increases, the values of $\xi^{*}, p^{*}$ will increase while the total profit $\pi^{*}$ decreases. The result is analogous to the study of Zhang et al. [36]. This indicates that if the replenishment cost per order becomes higher, the enterprise will try to lengthen the replenishment cycle as well as ordering more quantity; this will result in more time to recover the cost of preservation technology. In order to increase profit, it is necessary for the enterprise to increase the selling price of goods.

\section{Observations 2}

$S^{*}$ increases when the value of the parameters $b, \delta, t_{1}, c_{p}, c_{1}$ decreases and $a, c_{2}, c_{3}, \theta, I_{e}, M$ increases while $S^{*}$ decreases. Moreover, there is no effect on $S^{*}$ if the value of the parameters OC, $a_{1}$ changes. The retailer would want to store more products when the cost of purchasing is available at a lower rate. Consequently, when the manufacturer gives more significant trade credit period to retailers, the retailers would tend to increase the product inventory in order to attract more buyers and sell more products. 
TABLE 7. Sensitivity analysis with respect to different parameters.

\begin{tabular}{|c|c|c|c|c|c|c|c|}
\hline \multirow[t]{2}{*}{ Parameter } & \multirow{2}{*}{$\begin{array}{l}\% \text { Change } \\
\text { in parameters }\end{array}$} & \multicolumn{6}{|c|}{$\%$ Change in } \\
\hline & & $\pi^{*}$ & $S^{*}$ & $R^{*}$ & $p^{*}$ & $\xi^{*}$ & $T^{*}$ \\
\hline \multirow[t]{4}{*}{$b$} & -20 & 82.35 & 15.62 & -1.82 & 18.62 & 1.99 & 0 \\
\hline & -10 & 35.94 & 7.6 & -0.26 & 8.28 & 0.9 & 0 \\
\hline & 10 & -28.43 & -7.22 & -0.84 & -6.77 & -0.92 & 0 \\
\hline & 20 & -51.22 & -14.1 & -2.65 & -12.42 & -1.78 & 0 \\
\hline \multirow[t]{4}{*}{$a$} & -20 & -78.32 & -33.51 & -22.8 & -14.82 & -1.7 & 0.72 \\
\hline & -10 & -42.87 & -17.2 & -10.89 & -7.45 & -1.01 & 0 \\
\hline & 10 & 50.35 & 17.58 & 9.78 & 7.45 & 0.9 & 0 \\
\hline & 20 & 108.2 & 35.47 & 18.6 & 14.9 & 1.7 & 0 \\
\hline \multirow{4}{*}{$C_{p}$} & -20 & 9.3 & 4.6 & 4.19 & -1.47 & -15.95 & 0 \\
\hline & -10 & 4.51 & 2.18 & 2.09 & -0.72 & -7.59 & 0 \\
\hline & 10 & -4.27 & -1.99 & -2.09 & 0.69 & 6.95 & 0 \\
\hline & 20 & -8.34 & -3.82 & -4.17 & 1.36 & 13.37 & 0 \\
\hline \multirow[t]{4}{*}{$c_{1}$} & -20 & 25.81 & 13.39 & -15.54 & -3.4 & 19.6 & 0 \\
\hline & -10 & 12.27 & 6.57 & -7.33 & -1.64 & 9.4 & 0 \\
\hline & 10 & -11.13 & -6.29 & 6.51 & 1.53 & -8.78 & 0 \\
\hline & 20 & -21.23 & -12.28 & 12.28 & 2.94 & -17.06 & 0 \\
\hline \multirow[t]{4}{*}{$c_{2}$} & -20 & 0.22 & -0.25 & 0 & -0.06 & -0.19 & 0 \\
\hline & -10 & 0.11 & -0.12 & 0 & -0.03 & -0.09 & 0 \\
\hline & 10 & -0.11 & 0.12 & 0 & 0.03 & 0.09 & 0 \\
\hline & 20 & -0.21 & 0.24 & 0 & 0.06 & 0.19 & 0 \\
\hline \multirow[t]{4}{*}{$c_{3}$} & -20 & 1.91 & -2.21 & 10.07 & -0.53 & -1.69 & 0 \\
\hline & -10 & 0.91 & -1.04 & 4.79 & -0.25 & -0.8 & 0 \\
\hline & 10 & -0.82 & 0.94 & -4.36 & 0.22 & 0.72 & 0 \\
\hline & 20 & -1.58 & 1.8 & -8.36 & 0.42 & 1.38 & 0 \\
\hline \multirow[t]{4}{*}{$a_{1}$} & -20 & 0.04 & 0 & 0 & 0 & 25 & 0 \\
\hline & -10 & 0.04 & 0 & 0 & 0 & 11.11 & 0 \\
\hline & 10 & 0 & 0 & 0 & 0 & -9.09 & 0 \\
\hline & 20 & 0.1 & 0 & 0 & 0 & -16.67 & 0 \\
\hline \multirow[t]{4}{*}{$\theta$} & -20 & -13.36 & -9.69 & 2.27 & 1.98 & -29.99 & 0 \\
\hline & -10 & -6.13 & -4.56 & 1.02 & 0.9 & -14.34 & 0 \\
\hline & 10 & 5.25 & 4.1 & -0.83 & -0.76 & 13.26 & 0 \\
\hline & 20 & 9.8 & 7.81 & -1.5 & -1.41 & 25.63 & 0 \\
\hline \multirow[t]{4}{*}{$\delta$} & -20 & 3.44 & -3.38 & 20.08 & -0.67 & -2.43 & 0 \\
\hline & -10 & 1.57 & -1.55 & 9.12 & -0.31 & -1.12 & 0 \\
\hline & 10 & -1.34 & 1.33 & -7.7 & 0.27 & 0.97 & 0 \\
\hline & 20 & -2.49 & 2.48 & -14.29 & 0.5 & 1.81 & 0 \\
\hline \multirow[t]{4}{*}{$\mathrm{OC}$} & -20 & 9.55 & 0 & 0 & 0 & 0 & 0 \\
\hline & -10 & 4.78 & 0 & 0 & 0 & 0 & 0 \\
\hline & 10 & -4.78 & 0 & 0 & 0 & 0 & 0 \\
\hline & 20 & -9.55 & 0 & 0 & 0 & 0 & 0 \\
\hline \multirow[t]{4}{*}{$t_{1}$} & -20 & -2.67 & 0.75 & -0.61 & 0.41 & 1.08 & 0 \\
\hline & -10 & -1.34 & 0.37 & -0.3 & 0.21 & 0.55 & 0 \\
\hline & 10 & 1.35 & -0.36 & 0.29 & -0.21 & -0.56 & 0 \\
\hline & 20 & 2.7 & -0.7 & 0.57 & -0.41 & -1.12 & 0 \\
\hline \multirow[t]{4}{*}{$I_{e}$} & -20 & -4.17 & -1.36 & 1.2 & 0.31 & -0.35 & 0 \\
\hline & -10 & -2.09 & -0.67 & 0.6 & 0.15 & -0.17 & 0 \\
\hline & 10 & 2.1 & 0.67 & 0.59 & -0.15 & 0.17 & 0 \\
\hline & 20 & 4.2 & 1.33 & 1.18 & -0.3 & 0.34 & 0 \\
\hline
\end{tabular}


TABLE 7. continued.

\begin{tabular}{llllllll}
\hline \hline \multirow{2}{*}{ Parameter } & \% Change & \multicolumn{7}{c}{ \% Change in } \\
\cline { 3 - 8 } & in parameters & $\pi^{*}$ & $S^{*}$ & $R^{*}$ & $p^{*}$ & $\xi^{*}$ & $T^{*}$ \\
\hline \multirow{2}{*}{$M$} & -20 & 2.28 & -21.26 & -12.52 & -2.33 & -13.29 & -20 \\
& -10 & 1.64 & -10.56 & -6.23 & -1.14 & -6.59 & -10 \\
& 10 & -2.34 & 10.35 & 6.13 & 1.11 & 6.47 & 10 \\
& 20 & -5.2 & 20.41 & 12.11 & 2.2 & 12.82 & 20 \\
\hline
\end{tabular}

\section{Observations 3}

$R^{*}$ increases when the value of the parameters $\theta, I_{e}, \delta, c_{p}, c_{3}$ decreases and $a, c_{1}, b, t_{1}, M$ increases while $R^{*}$ decreases. Moreover, there is no effect on $R$ if the value of the parameters OC, $a_{1}, c_{2}$ changes. It is observed that with the increase in $\delta$, the amount of shortages decreases and when it approaches infinity, then there will be no shortages. This means that the optimal value of $R^{*}$ will be zero. The amount of shortages increases when the value of holding cost increases which is analogous to the study by Li et al. [12].

\section{Observations 4}

$p^{*}$ increases when the value of the parameters $b, \theta, a_{1}, I_{e}, c_{t}$ decreases and $b, I_{e}, t_{1}, \theta$ increases while $p^{*}$ decreases. Moreover, there is no effect on $p^{*}$ if the value of the parameters OC, $a_{1}$ changes, but there is a proportional relationship between $p^{*}$ and the value of the parameters $a, \delta, c_{p}, c_{2}, c_{3}, c_{1}, M$. However, when the selling price increases, the retailer would tend to sell more products so that the total cycle time will be longer and reduce the shortage in order to get maximum profit. When purchase cost increases, then optimal total profit $\left(\pi^{*}\right)$ and shortage $\left(R^{*}\right)$ decreases together with is the increase in selling price. The result of which is analogous to the study by Tiwari et al. [33].

\section{Observations 5}

$\xi^{*}$ increases when the value of the parameters $a, b t_{1}, c_{1}$ increases and $a, b t_{1}, c_{1}$, increases while $\xi^{*}$ decreases. Moreover, there is no effect on $\mathrm{R}$ if the value of the parameters OC changes, but there is a proportional relationship between $p^{*}$ and the value of the parameters $a, \delta, c_{p}, c_{2}, c_{3}, I_{e}, M, \theta$. When the value of the simulation coefficient $a_{1}$ increases, then the value of preservation investment decreases. It is also observed that the investment on preservation technology lengthened the non-deterioration period and reduced the deterioration, which is observed in the study by $\mathrm{Li}$ et al. [12].

\section{Observations 6}

$T^{*}$ increases when the value of the parameters $a, b$ decreases. Moreover, there is no effect on $R$ when the value of the parameters $\mathrm{OC}, a_{1}, c_{2}, c_{3}, c_{p}, c_{1}, I_{e}, t_{1}, \theta, \delta$ changes and there is a proportional relationship between total cycle length and trade credit period. This means that when the retailer gets more trade credit period, the retailer would lengthen the cycle length.

\section{Conclusions And COMments}

In this study, we have derived a deteriorating inventory model with price dependent demand, partial backlogging and trade credit considering preservation technology for perishable goods. It has been shown that the investment in preservation technology has lengthened the freshness of goods. Furthermore, to increase competitiveness, this model also takes into account of credit financing as a strategy that benefits retailers. We have derived the optimal cycle length, optimal selling price and investments in preservation technology in order to maximize the total profit. Numerical analysis is carried out to show the importance of preservation technology investment and trade credit policy. Finally, with the help of MATLAB 2017a software, it is shown graphically 
that the profit function is concave, and sensitivity analysis is done using Lingo17. The study provides insight for managers to make smart decisions especially in the scope of applying preservation technology and credit financing. The main limitation in the study is the assumption of fixed trade-credit period. For future research, this paper can be extended to consider some features such as probabilistic demand rate, variable trade-credit period, variable deterioration rate, quantity discounts, and multiple products.

\section{Appendix A.}

From equation (3.9):

$$
R=-I_{3}(T)=\frac{(a-b p)}{\delta}\left\{\log \left(1+\delta\left(T-t_{2}\right)\right)\right\}
$$

which implies that

$$
t_{2}=T+\frac{1}{\delta}\left(1-\mathrm{e}^{D \frac{R}{\delta}}\right)
$$

which can be written in the form

$$
t_{2}=T+f(D)
$$

Now putting the value of $t_{2}$ in equation (3.23) then it reduces to

$$
\begin{aligned}
& \pi^{3}(p, \xi, T)=\frac{1}{T}\left[\begin{array}{l}
p\left[(a-b p)(T+f(D))+\frac{(a-b p)}{\delta}\{\log (1+\delta(T-T-f(D)))\}\right]-A \\
-c\left[(a-b p) t_{1}+\frac{(a-b p)}{\theta m(\xi)}\left(\mathrm{e}^{\theta m(\xi)\left(T+f(D)-t_{1}\right)}-1\right)+\frac{(a-b p)}{\delta}\{\log (1+\delta(T-T-f(D)))\}\right] \\
-c_{1}\left[S t_{1}-\frac{(a-b p) t_{1}^{2}}{2}-\frac{(a-b p)}{\theta^{2} m(\xi)^{2}}\left(1-\mathrm{e}^{\theta m(\xi)\left(T+f(D)-t_{1}\right)}+\theta m(\xi)\left(T+f(D)-t_{1}\right)\right)\right] \\
-c_{2}\left[\left(R+\frac{D}{\delta}(T-T-f(D))\right)-\frac{D}{\delta^{2}}(1+\delta(T-T-f(D))) \log (1+\delta(T-T-f(D)))\right] \\
-\frac{c_{3}(a-b p)}{\delta}\{\delta(T-T-f(D))-\log (1-\delta(T-T-f(D)))\}+\frac{p I_{e}(a-b p)(T+f(D))^{2}}{2} \\
+\frac{p I_{e}(a-b p)(T+f(D))}{\delta} \log (1+\delta(T-T-f(D)))
\end{array}\right] \\
& =\frac{1}{T}\left[\begin{array}{l}
p\left[(a-b p)(T+f(D))+\frac{(a-b p)}{\delta}\{\log (1-\delta f(D))\}\right]-A \\
-c\left[(a-b p) t_{1}+\frac{(a-b p)}{\theta m(\xi)}\left(\mathrm{e}^{\theta m(\xi)\left(T+f(D)-t_{1}\right)}-1\right)+\frac{(a-b p)}{\delta}\{\log (1-\delta f(D))\}\right] \\
-c_{1}\left[S t_{1}-\frac{(a-b p) t_{1}^{2}}{2}-\frac{(a-b p)}{\theta^{2} m(\xi)^{2}}\left(1-\mathrm{e}^{\theta m(\xi)\left(T+f(D)-t_{1}\right)}+\theta m(\xi)\left(T+f(D)-t_{1}\right)\right)\right] \\
-c_{2}\left[\left(R-\frac{D}{\delta}(f(D))\right)-\frac{D}{\delta^{2}}(1-\delta(f(D)))\{\log (1-\delta f(D))\}\right] \\
-\frac{c_{3}(a-b p)}{\delta}\{-\delta(f(D))-\{\log (1-\delta f(D))\}\}+\frac{p I_{e}(a-b p)(T+f(D))^{2}}{2} \\
+\frac{p I_{e}(a-b p)(T+f(D))}{\delta}\{\log (1-\delta f(D))\}
\end{array}\right] \\
& =\frac{1}{T} G(p, \xi, T), \quad \text { since } D=a-b p
\end{aligned}
$$


Differentiate $X$ with respect to $\xi$ we have

$$
\begin{aligned}
\mathrm{SR} & =p\left[(a-b p) t_{2}+\frac{(a-b p)}{\delta}\left\{\log \left(1+\delta\left(T-t_{2}\right)\right)\right\}\right], \frac{\partial \mathrm{SR}}{\partial \xi}=\frac{\partial^{2} \mathrm{SR}}{\partial \xi}=0 \\
\mathrm{OC} & =A, \frac{\partial \mathrm{OC}}{\partial \xi}=0 \\
\mathrm{PC} & =c\left[(a-b p) t_{1}+\frac{(a-b p)}{\theta m(\xi)}\left\{\mathrm{e}^{\theta m(\xi)\left(t_{2}-t_{1}\right)}-1\right\}\right] \\
\frac{\partial \mathrm{PC}}{\partial \xi} & =c(a-b p)\left[-\mathrm{e}^{\theta m(\xi)\left(t_{2}-t_{1}\right)} \cdot \frac{1}{\theta m(\xi)^{2}} \cdot \frac{\mathrm{d} m(\xi)}{\mathrm{d} \xi}+\frac{1}{\theta m(\xi)} \cdot \mathrm{e}^{\theta m(\xi)\left(t_{2}-t_{1}\right)} \theta\left(t_{2}-t_{1}\right) \cdot \frac{\mathrm{d} m(\xi)}{\mathrm{d} \xi}\right] \\
& =c(a-b p) a_{1}\left[\mathrm{e}^{\theta m(\xi)\left(t_{2}-t_{1}\right)} \cdot \frac{1}{\theta m(\xi)}-\mathrm{e}^{\theta m(\xi)\left(t_{2}-t_{1}\right)}\left(t_{2}-t_{1}\right)\right] \\
\frac{\partial^{2} \mathrm{PC}}{\partial \xi^{2}} & =c(a-b p) a_{1}^{2} \mathrm{e}^{\theta m(\xi)\left(t_{2}-t_{1}\right)}\left(t_{2}-t_{1}\right)\left[1-\theta\left(t_{2}-t_{1}\right) \mathrm{e}^{-a_{1} \xi}\right]-c(a-b p) a_{1} \frac{\mathrm{e}^{\theta m(\xi)\left(t_{2}-t_{1}\right)}}{\theta m(\xi)^{2}} \\
\mathrm{BC} & =c_{2}\left(R+\frac{D}{\delta}\left(T-t_{2}\right)\right)-\frac{D}{\delta^{2}}\left(1+\delta\left(T-t_{2}\right)\right) \log \left(1+\delta\left(T-t_{2}\right)\right) \\
\frac{\partial \mathrm{BC}}{\partial \xi} & =\frac{\partial^{2} \mathrm{BC}}{\partial \xi^{2}}=0 \\
\mathrm{LSC} & =\frac{c_{3}(a-b p)}{\delta}\left\{\delta\left(T-t_{2}\right)-\log \left(1+\delta\left(T-t_{2}\right)\right)\right\} \Rightarrow \frac{\partial \mathrm{LSC}}{\partial \xi}=\frac{\partial^{2} \mathrm{LSC}}{\partial \xi^{2}}=0 \\
\mathrm{IE} \mathrm{E}_{3} & =\frac{p I_{e}(a-b p) t_{2}^{2}}{2}+\frac{p I_{e}(a-b p) t_{2}}{\delta} \log \left(1+\delta\left(T-t_{2}\right)\right), \frac{\partial E_{1}}{\partial \xi}=\frac{\partial^{2} E_{1}}{\partial \xi^{2}}=0 \\
\mathrm{PTC} & =\xi T \Rightarrow \frac{\partial \mathrm{PTC}}{\partial \xi}=T \text { and } \frac{\partial^{2} \mathrm{PTC}}{\partial \xi^{2}}=0 .
\end{aligned}
$$

Differentiating $X$ with respect to " $p$ " shows

$$
\begin{gathered}
\mathrm{SR}=p\left[(a-b p) t_{2}+\frac{(a-b p)}{\delta}\left\{\log \left(1+\delta\left(T-t_{2}\right)\right)\right\}\right], \\
\frac{\partial^{2} \mathrm{SR}}{\partial p^{2}}=\left[-2 b t_{2}-\frac{2 b}{\delta}\left\{\log \left(1+\delta\left(T-t_{2}\right)\right)\right\}\right] \\
\mathrm{OC}=A, \frac{\partial \mathrm{OC}}{\partial p}=\frac{\partial^{2} \mathrm{OC}}{\partial p^{2}}=0 \\
\mathrm{PC}=c Q=c\left[(a-b p) t_{1}+\frac{(a-b p)}{\theta m(\xi)}\left(\mathrm{e}^{\theta m(\xi)\left(t_{2}-t_{1}\right)}-1\right)+\frac{(a-b p)}{\delta}\left\{\log \left(1+\delta\left(T-t_{2}\right)\right)\right\}\right] \\
\frac{\partial \mathrm{PC}}{\partial p}=-b c\left[t_{1}+\frac{1}{\theta m(\xi)}\left(\mathrm{e}^{\theta m(\xi)\left(t_{2}-t_{1}\right)}-1\right)+\frac{1}{\delta}\left\{\log \left(1+\delta\left(T-t_{2}\right)\right)\right\}\right] \Rightarrow \frac{\partial^{2} \mathrm{PC}}{\partial p^{2}}=0 \\
\mathrm{IHC}=c_{1}\left[s t_{1}-\frac{(a-b p) t_{1}^{2}}{2}-\frac{(a-b p)}{\theta^{2} m(\xi)^{2}}\left\{1-\mathrm{e}^{\theta m(\xi)\left(t_{2}-t_{1}\right)}+\theta m(\xi)\left(t_{2}-t_{1}\right)\right\}\right] \\
\frac{\partial \mathrm{IHC}}{\partial p}=c_{1}\left[\frac{1}{2} b t_{1}^{2}+\frac{b}{\theta^{2} m(\xi)^{2}}\left\{1-\mathrm{e}^{\theta m(\xi)\left(t_{2}-t_{1}\right)}+\theta m(\xi)\left(t_{2}-t_{1}\right)\right\}\right] \Rightarrow \frac{\partial^{2} \mathrm{IHC}}{\partial p^{2}}=0 \\
\mathrm{BC}=c_{2}\left[\left(R+\frac{a-b p}{\delta}\left(T-t_{2}\right)\right)-\frac{a-b p}{\delta^{2}}\left(1+\delta\left(T-t_{2}\right)\right) \log \left(1+\delta\left(T-t_{2}\right)\right)\right] \\
\frac{\partial \mathrm{BC}}{\partial p}=c_{2}\left[\left(\frac{b}{\delta}\left(t_{2}-T\right)\right)+\frac{b}{\delta^{2}}\left(1+\delta\left(T-t_{2}\right)\right) \log \left(1+\delta\left(T-t_{2}\right)\right)\right] \Rightarrow \frac{\partial^{2} \mathrm{BC}}{\partial p^{2}}=0
\end{gathered}
$$




$$
\begin{aligned}
\mathrm{LSC} & =\frac{c_{3}(a-b p)}{\delta}\left\{\delta\left(T-t_{2}\right)-\log \left(1+\delta\left(T-t_{2}\right)\right)\right\} \\
\frac{\partial \mathrm{LSC}}{\partial p} & =-\frac{c_{3} b}{\delta}\left\{\delta\left(T-t_{2}\right)-\log \left(1+\delta\left(T-t_{2}\right)\right)\right\} \Rightarrow \frac{\partial^{2} \mathrm{LSC}}{\partial p^{2}}=0 \\
\mathrm{IE}_{3} & =\frac{p I_{e}(a-b p) t_{2}^{2}}{2}+\frac{p I_{e}(a-b p) t_{2}}{\delta} \log \left(1+\delta\left(T-t_{2}\right)\right) \\
\frac{\partial E_{3}}{\partial p} & =\frac{I_{e}(a-2 b p) t_{2}^{2}}{2}+\frac{I_{e}(a-2 b p) t_{2}}{\delta} \log \left(1+\delta\left(T-t_{2}\right)\right) \\
\frac{\partial^{2} E_{3}}{\partial p^{2}} & =-\frac{I_{e} b t_{2}^{2}}{2}-\frac{I_{e} b t_{2}}{\delta} \log \left(1+\delta\left(T-t_{2}\right)\right) .
\end{aligned}
$$

Differentiating $X$ with respect to " $T$ " shows

$$
\begin{gathered}
\mathrm{SR}=p\left[(a-b p) t_{2}+\frac{(a-b p)}{\delta}\left\{\log \left(1+\delta\left(T-t_{2}\right)\right)\right\}\right] \\
\frac{\partial \mathrm{SR}}{\partial T}=\frac{p(a-b p)}{\left(1+\delta\left(T-t_{2}\right)\right.} ; \mathrm{OC}=A, \frac{\partial \mathrm{OC}}{\partial T}=0 \\
\mathrm{PC}=c\left[(a-b p) t_{1}+\frac{(a-b p)}{\theta m(\xi)}\left\{\mathrm{e}^{\theta m(\xi)\left(t_{2}-t_{1}\right)}-1\right\}\right] \\
\frac{\partial \mathrm{PC}}{\partial T}=\frac{c(a-b p)}{\left(1+\delta\left(T-t_{2}\right)\right.} \\
\mathrm{IHC}=c_{1}\left[s t_{1}-\frac{(a-b p) t_{1}^{2}}{2}-\frac{(a-b p)}{\theta^{2} m(\xi)^{2}}\left\{1-\mathrm{e}^{\theta m(\xi)\left(t_{2}-t_{1}\right)}+\theta m(\xi)\left(t_{2}-t_{1}\right)\right\}\right], \frac{\partial \mathrm{IHC}}{\partial T}=0 \\
\frac{\partial \mathrm{BC}}{\partial T}=\frac{c_{2}(a-b p)}{\delta}\left(1+\delta\left(T-t_{2}\right)\left(T-t_{2}\right)+c_{2} \frac{a-b p}{\delta^{2}}\left[\left(1+\delta\left(T-t_{2}\right)\left\{\log \left(1+\delta\left(T-t_{2}\right)\right)-1\right\}+1\right]\right.\right. \\
\mathrm{LSC}=\frac{c_{3}(a-b p)}{\delta}\left\{\delta\left(T-t_{2}\right)-\log \left(1+\delta\left(T-t_{2}\right)\right)\right\} \\
\frac{\partial \mathrm{LSC}}{\partial T}=c_{3}(a-b p)\left[1-\frac{1}{\left(1+\delta\left(T-t_{2}\right)\right)}\right] \\
\mathrm{IE}=\frac{p I_{e}(a-b p) t_{2}^{2}}{2}+\frac{p I_{e}(a-b p) t_{2}}{\delta} \log \left(1+\delta\left(T-t_{2}\right)\right) \Rightarrow \frac{\partial E_{3}}{\partial T}=\frac{p I_{e}(a-b p) t^{2}}{\left(1+\delta\left(T-t_{2}\right)\right)} \\
\mathrm{PTC}=\xi T, \Rightarrow \frac{\partial \mathrm{PTC}}{\partial T}=\xi
\end{gathered}
$$

\section{Appendix B.}

\section{Proof of Corollary 4.1}

The objective function is

$$
\pi^{3}(p, \xi, T)=\frac{X}{T}
$$


Differentiating the equation (B.1) with respect to $T$,

$$
\frac{\partial \pi^{3}(p, \xi, T)}{\partial T}=\frac{T \frac{\partial X}{\partial T}-X}{T^{2}} .
$$

Differentiating the equation (B.2) with respect to $T$,

$$
\begin{aligned}
\frac{\partial^{2} \pi^{3}(p, \xi, T)}{\partial T^{2}} & =\frac{T^{2}\left\{\frac{\partial X}{\partial T}+T \frac{\partial^{2} X}{\partial T^{2}}-\frac{\partial X}{\partial T}\right\}-2 T\left\{T \frac{\partial X}{\partial T}-X\right\}}{T^{3}} \\
& =\frac{T^{2} \frac{\partial^{2} X}{\partial T^{2}}-2 T \frac{\partial X}{\partial T}+2 X}{T^{3}} .
\end{aligned}
$$

From equation (B.3) we observed that

$$
\frac{\partial^{2} \pi^{3}(p, \xi, T)}{\partial T^{2}}<0
$$

which means

$$
\begin{aligned}
\frac{T^{2} \frac{\partial^{2} X}{\partial T^{2}}-2 T \frac{\partial X}{\partial T}+2 X}{T^{3}}<0, & \Rightarrow \frac{1}{T} \frac{\partial^{2} X}{\partial T^{2}}-\frac{2}{T^{2}} \frac{\partial X}{\partial T}+\frac{2 X}{T^{3}}<0 \\
& \Rightarrow \frac{1}{T} \frac{\partial^{2} X}{\partial T^{2}}+\frac{2 X}{T^{3}}<\frac{2}{T^{2}} \frac{\partial X}{\partial T}
\end{aligned}
$$

\section{Proof of Corollary 4.2}

For any fixed $\xi$ and $T$, the second order derivative of the objective function $\pi^{3}(p, \xi, T)$ with respect to the decision variables $p$ is

$$
\frac{\partial^{2} \pi^{3}(p, \xi, T)}{\partial p^{2}}=-\frac{1}{T}\left[2 b t_{2}+\frac{2 b}{\delta}\left\{\log \left(1+\delta\left(T-t_{2}\right)\right)\right\}-\frac{I_{e} b t_{2}^{2}}{2}+\frac{I_{e} b t_{2}}{\delta} \log \left(1+\delta\left(T-t_{2}\right)\right)\right]<0
$$

which implies that, $\left[2 b t_{2}+\frac{2 b}{\delta}\left\{\log \left(1+\delta\left(T-t_{2}\right)\right)\right\}-\frac{I_{e} b t_{2}^{2}}{2}+\frac{I_{e} b t_{2}}{\delta} \log \left(1+\delta\left(T-t_{2}\right)\right)\right]>0$, since $T$ is the total cycle length

$$
\begin{aligned}
& \Rightarrow 4 t_{2}+\left(\frac{4}{\delta}+\frac{2 I_{e} t_{2}}{\delta}\right) \log \left(1+\delta\left(T-t_{2}\right)\right)>I_{e} t_{2}^{2} \\
& \Rightarrow\left(\frac{4}{\delta}+\frac{2 I_{e} t_{2}}{\delta}\right) \log \left(1+\delta\left(T-t_{2}\right)\right)>I_{e} t_{2}^{2}-4 t_{2} \\
& \Rightarrow \log \left(1+\delta\left(T-t_{2}\right)\right)>\frac{I_{e} \delta\left(t_{2}-4\right) t_{2}}{2 I_{e} t_{2}+4} W .
\end{aligned}
$$

Now the mixed derivatives with respect to the decision variables

$$
\begin{aligned}
& \frac{\partial^{2} \pi^{3}(p, \xi, T)}{\partial \xi \partial p}=\frac{1}{T}\left[\begin{array}{l}
a_{1} b c\left[\frac{\mathrm{e}^{\theta m(\xi)\left(t_{2}-t_{1}\right)}}{\theta m(\xi)}+\mathrm{e}^{\theta m(\xi)\left(t_{2}-t_{1}\right)}\left(t_{2}-t_{1}\right)\right] \\
-c_{1} a_{1}\left[\frac{2 b}{\theta^{2}} \frac{1}{m(\xi)^{2}}+\frac{1}{\theta} \mathrm{e}^{\theta m(\xi)\left(t_{2}-t_{1}\right)}-\frac{b}{\theta m(\xi)}\left(t_{2}-t_{1}\right)\right]
\end{array}\right] \\
& \frac{\partial^{2} \pi^{3}(p, \xi, T)}{\partial \xi \partial T}=-\frac{1}{T^{2}}\left[\begin{array}{l}
-c a_{1}(a-b p)\left[\frac{\mathrm{e}^{\theta m(\xi)\left(t_{2}-t_{1}\right)}}{\theta m(\xi)}-\mathrm{e}^{\theta m(\xi)\left(t_{2}-t_{1}\right)}\left(t_{2}-t_{1}\right)\right] \\
-c_{1} a_{1}\left[\begin{array}{l}
-\frac{2(a-b p)}{\theta^{2}} \frac{1}{m(\xi)^{2}}-\frac{(a-b p)}{\theta} \mathrm{e}^{\theta m(\xi)\left(t_{2}-t_{1}\right)}+\mathrm{e}^{\theta m(\xi)\left(t_{2}-t_{1}\right)} \frac{2}{\theta^{2}} \frac{1}{m(\xi)^{2}} \\
+\frac{(a-b p)}{\theta m(\xi)}\left(t_{2}-t_{1}\right)
\end{array}\right]-1
\end{array}\right]
\end{aligned}
$$




$$
\begin{aligned}
& \frac{\partial^{2} \pi^{3}(p, \xi, T)}{\partial p \partial \xi}=\frac{1}{T}\left[\begin{array}{l}
a_{1} b c\left[\frac{1}{\theta m(\xi)}\left(\mathrm{e}^{\theta m(\xi)\left(t_{2}-t_{1}\right)}-1\right)-\mathrm{e}^{\theta m(\xi)\left(t_{2}-t_{1}\right)}\left(t_{2}-t_{1}\right)\right] \\
-c_{1} b a_{1}\left[\frac{2}{\theta^{2} m(\xi)^{2}}\left\{1-\mathrm{e}^{\theta m(\xi)\left(t_{2}-t_{1}\right)}+\theta m(\xi)\left(t_{2}-t_{1}\right)\right\}+\frac{\left(t_{2}-t_{1}\right)}{\theta m(\xi)}\left\{\mathrm{e}^{\theta m(\xi)\left(t_{2}-t_{1}\right)}-1\right\}\right]
\end{array}\right] \\
& \frac{\partial^{2} \pi^{3}(p, \xi, T)}{\partial p \partial T}=-\frac{1}{T^{2}}\left[\begin{array}{l}
(a-2 b p) t_{2}+\frac{(a-2 b p)}{\delta}\left\{\log \left(1+\delta\left(T-t_{2}\right)\right)\right\}+b c\left[\begin{array}{l}
t_{1}+\frac{1}{\theta m(\xi)}\left(\mathrm{e}^{\theta m(\xi)\left(t_{2}-t_{1}\right)}-1\right) \\
+\frac{1}{\delta}\left\{\log \left(1+\delta\left(T-t_{2}\right)\right)\right\}
\end{array}\right] \\
-c_{1}\left[\frac{1}{2} b t_{1}^{2}+\frac{b}{\theta^{2} m(\xi)^{2}}\left\{1-\mathrm{e}^{\theta m(\xi)\left(t_{2}-t_{1}\right)}+\theta m(\xi)\left(t_{2}-t_{1}\right)\right\}\right] \\
-c_{2}\left[\left(\frac{b}{\delta}\left(t_{2}-T\right)\right)+\frac{b}{\delta^{2}}\left(1+\delta\left(T-t_{2}\right)\right) \log \left(1+\delta\left(T-t_{2}\right)\right)\right] \\
+\frac{c_{3} b}{\delta}\left\{\delta\left(T-t_{2}\right)-\log \left(1+\delta\left(T-t_{2}\right)\right)\right\}-\frac{I_{e}(a-2 b p) t_{2}^{2}}{2} \\
+\frac{I_{e}(a-2 b p) t_{2}}{\delta} \log \left(1+\delta\left(T-t_{2}\right)\right)
\end{array}\right] \\
& +\frac{1}{T}\left[\begin{array}{l}
\frac{(a-2 b p)}{1+\delta\left(T-t_{2}\right)}+b c\left[\frac{1}{1+\delta\left(T-t_{2}\right)}\right]-c_{2}\left[\left(-\frac{b}{\delta}\right)+\frac{b}{\delta} \log \left(1+\delta\left(T-t_{2}\right)\right)+\delta\right] \\
+c_{3} b\left\{1-\frac{1}{1+\delta\left(T-t_{2}\right)}\right\}+\frac{I_{e}(a-2 b p) t_{2}}{1+\delta\left(T-t_{2}\right)}
\end{array}\right] \\
& \frac{\partial^{2} \pi^{3}(p, \xi, T)}{\partial T \partial p}=-\frac{1}{T}\left[\begin{array}{l}
(a-2 b p) t_{2}+\frac{(a-2 b p)}{\delta}\left\{\log \left(1+\delta\left(T-t_{2}\right)\right)\right\} \\
+b c\left[t_{1}+\frac{1}{\theta m(\xi)}\left(\mathrm{e}^{\theta m(\xi)\left(t_{2}-t_{1}\right)}-1\right)+\frac{1}{\delta}\left\{\log \left(1+\delta\left(T-t_{2}\right)\right)\right\}\right] \\
-c_{2}\left[\left(\frac{1}{\delta} b t_{1}^{2}+\frac{b}{\theta^{2} m(\xi)^{2}}\left\{1-\mathrm{e}^{\theta m(\xi)\left(t_{2}-t_{1}\right)}+\theta m(\xi)\left(t_{2}-t_{1}\right)\right\}\right]+\frac{b}{\delta^{2}}\left(1+\delta\left(T-t_{2}\right)\right) \log \left(1+\delta\left(T-t_{2}\right)\right)\right] \\
+\frac{c_{3} b}{\delta}\left\{\delta\left(T-t_{2}\right)-\log \left(1+\delta\left(T-t_{2}\right)\right)\right\}-\frac{I_{e}(a-2 b p) t_{2}^{2}}{2} \\
+\frac{I_{e}(a-2 b p) t_{2}}{\delta} \log \left(1+\delta\left(T-t_{2}\right)\right)
\end{array}\right] \\
& +\frac{1}{T}\left[\begin{array}{l}
\frac{a+b c-2 b p}{1+\delta\left(T-t_{2}\right)}-\frac{c_{2} b}{\delta} \log \left(1+\delta\left(T-t_{2}\right)\right) \\
-c_{3} b\left[1-\frac{1}{1+\delta\left(T-t_{2}\right)}\right]-\frac{I_{e}(a-2 b p) t_{2}}{1+\delta\left(T-t_{2}\right)}
\end{array}\right] \\
& \frac{\partial^{2} \pi^{3}(p, \xi, T)}{\partial T \partial \xi}=-\frac{1}{T}\left[\begin{array}{l}
-c a_{1}(a-b p)\left[\frac{\mathrm{e}^{\theta m(\xi)\left(t_{2}-t_{1}\right)}}{\theta m(\xi)}-\mathrm{e}^{\theta m(\xi)\left(t_{2}-t_{1}\right)}\left(t_{2}-t_{1}\right)\right] \\
-c_{1} a_{1}\left[\begin{array}{l}
-\frac{2(a-b p)}{\theta^{2}} \frac{1}{m(\xi)^{2}}-\frac{(a-b p)}{\theta} \mathrm{e}^{\theta m(\xi)\left(t_{2}-t_{1}\right)}+\mathrm{e}^{\theta m(\xi)\left(t_{2}-t_{1}\right)} \frac{2}{\theta^{2}} \frac{1}{m(\xi)^{2}} \\
+\frac{(a-b p)}{\theta m(\xi)}\left(t_{2}-t_{1}\right)
\end{array}\right]
\end{array}\right] .
\end{aligned}
$$

Acknowledgements. We want to thank the editor and the reviewers for their constructive comments and suggestions. This research received no external funding. 


\section{REFERENCES}

[1] S.P. Aggarwal and C.K. Jaggi, Ordering policies of deteriorating items under permissible delay in payments. J. Oper. Res. Soc. 46 (1995) 658-662.

[2] R. Begum, R.R. Sahoo and S.K. Sahu, A replenishment policy for items with price-dependent demand, time-proportional deterioration and no shortages. Int. J. Syst. Sci. 43 (2012) 903-910.

[3] S.C. Chen and J.T. Teng, Inventory and credit decisions for time-varying deteriorating items with up-stream and down-stream trade credit financing by discounted cash flow analysis. Eur. J. Oper. Res. 243 (2015) 566-575.

[4] A. Cambini and L. Martein, Generalized convexity and optimization: Theory and application. Springer-Verlag Berlin Heidelberg, USA (2009).

[5] B.K. Dey, B. Sarkar, M. Sarkar and S. Pareek, An integrated inventory model involving discrete Setup cost reduction, variable safety factor, selling price dependent demand, and investment. RAIRO: OR 53 (2019) 39-57.

[6] C.Y. Dye, The effect of preservation technology investment on a non-instantaneous deteriorating inventory model. Omega 41 (2013) 872-880.

[7] C.Y. Dye and T.P. Hsieh, An optimal replenishment policy for deteriorating items with effective investment in preservation technology. Eur. J. Oper. Res. 218 (2012) 106-112.

[8] S.K. Goyal, Economic order quantity under conditions of permissible delay in payments. J. Oper. Res. Soc. 36 (1985) 335-338.

[9] Y. He and H. Huang, Optimizing inventory and pricing policy for seasonal deteriorating products with preservation technology investment J. Ind. Eng. 2013 (2013) 793568.

[10] T.P. Hsieh and C.Y. Dye, A production-inventory model incorporating the effect of preservation technology investment when demand is fluctuating with time. J. Comput. Appl. Math. 239 (2013) 25-36.

[11] C.K. Jaggi, S. Tiwari and S.K. Goel, Credit financing in economic ordering policies for non-instantaneous deteriorating items with price dependent demand and two storage facilities. Ann. Oper. Res. 248 (2017) 253-280.

[12] G. Li, X. He, J. Zhou and H. Wu, Pricing, replenishment and preservation technology investment decisions for non-instantaneous deteriorating items. Omega 84 (2018) 114-126.

[13] G. Liu, J. Zhang and W. Tang, Joint dynamic pricing and investment strategy for perishable foods with price-quality dependent demand. Ann. Oper. Res. 226 (2015) 397-416.

[14] L. Lu, J. Zhang and W. Tang, Optimal dynamic pricing and replenishment policy for perishable items with inventory-leveldependent demand. Int. J. Syst. Sci. 47 (2016) 1480-1494.

[15] A. Mashud, M. Khan, M. Uddin and M. Islam, A non-instantaneous inventory model having different deterioration rates with stock and price dependent demand under partially backlogged shortages. Uncertain Supply Chain Manage. 6 (2018) 49-64.

[16] V.K. Mishra, Controllable deterioration rate for time-dependent demand and time-varying holding cost. Yugoslav J. Oper. Res. 24 (2014) 87-98.

[17] V.K. Mishra, An inventory model of instantaneous deteriorating items with controllable deterioration rate for time dependent demand and holding cost. J. Ind. Eng. Manage. 6 (2013) 495-506.

[18] U. Mishra, J.T. Aguilera, S. Tiwari and L.E.C. Barron, Retailer's joint ordering, pricing, and preservation technology investment policies for a deteriorating item under permissible delay in payments. Math. Probl. Eng. 5 (2018) 1-14

[19] A.H. Nobil, L.E. Cáardenas-Barr and E. Nobil, Optimal and simple algorithms to solve integrated procurement-productioninventory problem without/with shortage. RAIRO: OR 52 (2018) 755-778.

[20] A.H. Nobil, A. Kazemi and A.A. Taleizadeh, Single-machine lot scheduling problem for deteriorating items with negative exponential deterioration rate. RAIRO: OR 53 (2019) 1297-1307.

[21] A.H. Nobil, A. Kazemi and A.A. Taleizadeh, Economic lot-size problem for a cleaner manufacturing system with warm-up period. RAIRO: OR 54 (2020) 1495-1514.

[22] R. Pandey, S. Singh, B. Vaish and S. Tayal, An EOQ model with quantity incentive strategy for deteriorating items and partial backlogging. Uncertain Supply Chain Manage. 5 (2017) 135-142.

[23] B. Pal, Optimal production model with quality sensitive market demand, partial backlogging and permissible delay in payment. RAIRO: OR 52 (2018) 499-512.

[24] M. Palanivel and R. Uthayakumar, An inventory model with imperfect items, stock dependent demand and permissible delay in payments under inflation. RAIRO: OR 50 (2016) 473-489.

[25] B. Sarkar and S. Sarkar, An improved model with partial backlogging, time varying deterioration and stock-dependent demand. Econ. Model. 30 (2013) 924-932.

[26] B.K. Sett, B. Sarkar and A. Goswami, A two-warehouse inventory model with increasing demand and time varying deterioration. Sci. Iran. 19 (2012) 1969-1977.

[27] N.H. Shah, H.N. Soni and K.A. Patel, Optimizing inventory and marketing policy for non-instantaneous deteriorating items with generalized type deterioration and holding cost rates. Omega 41 (2013) 421-430.

[28] A.A. Shaikh, A.H.M. Mashud, M.S. Uddin, and M.A.A. Khan, Non instantaneous deterioration inventory model with price and stock dependent demand for fully backlogged shortages under inflation. Int. J. Bus. Forecasting Marketing Intell. 3 (2017) $152-164$.

[29] S. Singh, D. Khurana and S. Tayal, An economic order quantity model for deteriorating products having stock dependent demand with trade credit period and preservation technology. Uncertain Supply Chain Manage. 4 (2016) $29-42$.

[30] J.T. Teng, J. Min and Q. Pan, Economic order quantity model with trade credit financing for non-decreasing demand. Omega 40 (2012) 328-335. 
[31] S. Tiwari, L.E. Cárdenas-Barrón, A. Khanna and C.K. Jaggi, Impact of trade credit and inflation on retailer's ordering policies for non-instantaneous deteriorating items in a two-warehouse environment. Int. J. Prod. Econ. 176 (2016) 154-169.

[32] S. Tiwari, H.M. Wee and S. Sarkar, Lot-sizing policies for defective and deteriorating items with time-dependent demand and trade credit. Eur. J. Ind. Eng. 11 (2017) 683-703.

[33] S. Tiwari, L.E. Cárdenas-Barrón, M. Goh and A.A. Shaikh, Joint pricing and inventory model for deteriorating items with expiration dates and partial backlogging under two-level partial trade credits in supply chain. Int. J. Prod. Econ. 200 (2018) $16-36$.

[34] Y.C. Tsao and G.J. Sheen, Dynamic pricing, promotion and replenishment policies for a deteriorating item under permissible delay in payments. Comput. Oper. Res. 35 (2008) 3562-3580.

[35] C.T. Yang, C.Y. Dye and J.F. Ding, Optimal dynamic trade credit and preservation technology allocation for a deteriorating inventory model. Comput. Ind. Eng. 87 (2015) 356-369.

[36] J. Zhang, Z. Bai and W. Tang, Optimal pricing policy for deteriorating items with preservation technology investment. J. Ind. Manage. Optim. 10 (2014) 1261-1277. 